\title{
Peptide-mediated Cell Transport of Water Soluble Porphyrin Conjugates
}

Martha Sibrian-Vazquez, Timothy J. Jensen, Robert P. Hammer and M. Graça H. Vicente*

Department of Chemistry, Louisiana State University, Baton Rouge LA, 70803, USA.

\section{SUPPORTING INFORMATION:}

I. Synthesis of PEG linker (experimental details and characterization)

II. CD Spectra (amide and Soret regions)

III. HPLC conditions and traces for conjugates 4, 5, 6, 10 and 11

IV. ${ }^{1} \mathrm{H}$ NMR and ${ }^{13} \mathrm{CNMR}$ spectra

V. Intracellular localization for conjugates 5, 6 and 11 


\section{Scheme S1 ${ }^{a}$}

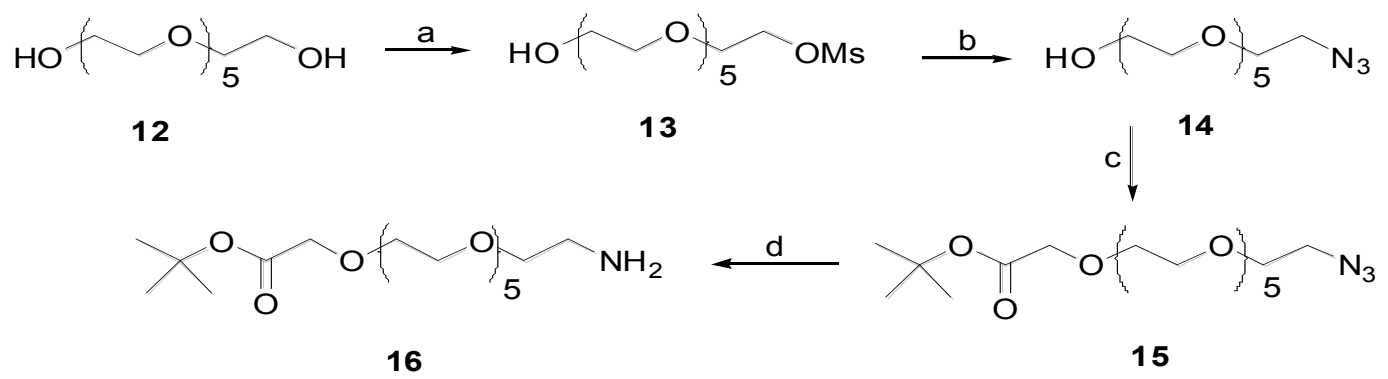

${ }^{a}$ Reaction conditions: (a) $\mathrm{MsCl} / \mathrm{Ag}_{2} \mathrm{O}, \mathrm{CH}_{2} \mathrm{Cl}_{2}, 48 / \mathrm{rt}, 49 \%$. (b) $\mathrm{NaN}_{3}, \mathrm{DMF}, 110{ }^{\circ} \mathrm{C} / 2.5 \mathrm{~h}, 98 \%$ yield. (c) $\mathrm{NaH} / \mathrm{THF} / \mathrm{BrCH}_{2} \mathrm{CO}_{2} t$-Bu, reflux/15h, Ar, 87\%. (d) $\mathrm{PPh}_{3} / \mathrm{THF} / \mathrm{H}_{2} \mathrm{O}, \mathrm{rt} / 24 \mathrm{~h}, 80 \%$.

Compound 13. Methane sulfonyl chloride $(0.487 \mathrm{~g}, 4.25 \mathrm{mmol})$ was dissolved in $2 \mathrm{~mL}$ of DCM and added to a mixture of hexaethylene glycol $12(1.0 \mathrm{~g}, 3.54 \mathrm{mmol})$ and $\mathrm{Ag}_{2} \mathrm{O}(0.902 \mathrm{~g}, 3.89 \mathrm{mmol})$ in $8 \mathrm{~mL}$ of DCM. The reaction mixture was stirred at room temperature $48 \mathrm{~h}$ and then filtered through celite. Evaporation of the solvent followed by flash chromatography using EtOAc:MeOH 10:1 for elution gave the target product as a colorless oil in $49 \%$ yield, (0.622g). HPLC Solvent System 8: $t_{r}=3.67 \mathrm{~min} .{ }^{1} \mathrm{H}$ NMR $\left(\mathrm{CDCl}_{3}, 250 \mathrm{MHz}\right): \delta 4.17-4.20(2 \mathrm{H}, \mathrm{m}), 3.38-3.53(20 \mathrm{H}, \mathrm{m}), 3.11(1 \mathrm{H}, \mathrm{s}), 2.91(3 \mathrm{H}, \mathrm{s}) .{ }^{13} \mathrm{C}$ NMR $\left(\mathrm{CDCl}_{3}, 62.5 \mathrm{MHz}\right): \delta \quad 72.01,69.95,69.90,69.67,69.02,68.37,60.91,37.03 . \mathrm{LRMS}(\mathrm{ESI}) \mathrm{m} / \mathrm{z}$ $\left(\mathrm{M}+\mathrm{Na}^{+}\right) 383.19$ calculated for $\mathrm{C}_{13} \mathrm{H}_{28} \mathrm{O}_{9} \mathrm{SNa} 383.13$.

Compound 14. Sodium azide $(0.168 \mathrm{~g}, 2.58 \mathrm{mmol})$ was added to a solution of $\mathbf{1 3}(0.622 \mathrm{~g}, 1.726 \mathrm{mmol})$ in $4 \mathrm{~mL}$ of dry DMF. The reaction mixture was heated at $110^{\circ} \mathrm{C} / 2.5 \mathrm{~h}$ and then cooled to rt. The reaction mixture was then co-evaporated with toluene at $50{ }^{\circ} \mathrm{C}$ and the residue purified by flash chromatography using as eluent EtOAc:MeOH 10:1. The product was isolated as a pale yellow oil in 98\% yield, (0.52g). HPLC Solvent System $8^{\mathrm{a}}: t_{r}=3.63 \mathrm{~min} .{ }^{1} \mathrm{H}$ NMR $\left(\mathrm{CDCl}_{3}, 250 \mathrm{MHz}\right): \delta$ 3.47-3.56 $(22 \mathrm{H}, \mathrm{m}), 3.26(2 \mathrm{H}, \mathrm{t}, J=4.99 \mathrm{~Hz}), 3.07(1 \mathrm{H}, \mathrm{s}) .{ }^{13} \mathrm{C} \mathrm{NMR}\left(\mathrm{CDCl}_{3}, 62.5 \mathrm{MHz}\right): \delta 72.88,70.98,70.86$, $70.75,70.73,70.66,70.41,70.34,70.31,70.28,70.25,70.22,61.71,50.79,36.65,31.55$. LRMS (ESI) $m / z\left(\mathrm{M}+\mathrm{Na}^{+}\right) 330.17$ calculated for $\mathrm{C}_{12} \mathrm{H}_{25} \mathrm{~N}_{3} \mathrm{O}_{6} \mathrm{Na} 330.34$. 
Compound 15. Under Ar atm. compound $14(0.431 \mathrm{~g}, 1.402 \mathrm{mmol})$ was dissolved in $25 \mathrm{~mL}$ of anhydrous THF. The solution was cooled to $0{ }^{\circ} \mathrm{C}$ and then $\mathrm{NaH}$ (60\% dispersion in mineral oil) $(0.070 \mathrm{~g}, 2.10 \mathrm{mmol})$ was added. The reaction mixture was kept a $0{ }^{\circ} \mathrm{C}$ for $20 \mathrm{~min}$ and then it was allowed to warm to room temperature and stirred for an additional $1 \mathrm{~h}$. $\mathrm{BrCH}_{2} \mathrm{CO}_{2} t$ - $\mathrm{Bu}$ was added in one portion and the reaction mixture refluxed $15 \mathrm{~h}$. Then the reaction mixture was cooled to room temperature and the solvent evaporated under vacuum. The title compound was separated and isolated by flash chromatography on silica gel using EtOAc:MeOH 9:1 for elution in 87\%yield, (0.513g). HPLC Solvent System 8: $t_{r}=8.39 \mathrm{~min} .{ }^{1} \mathrm{H}$ NMR $\left(\mathrm{CDCl}_{3}, 250 \mathrm{MHz}\right): \delta 3.87(2 \mathrm{H}, \mathrm{s}), 3.43-3.47(20 \mathrm{H}$, $\mathrm{m}), 3.17(2 \mathrm{H}, \mathrm{t}, J=6.24 \mathrm{~Hz}), 1.26(9 \mathrm{H}, \mathrm{s}) .{ }^{13} \mathrm{C} \mathrm{NMR}\left(\mathrm{CDCl}_{3}, 62.5 \mathrm{MHz}\right): \delta 168.98,81.98,80.67,70.01$, 69.94, 69.41, 68.32, 50.01, 27.46. LRMS (ESI) $\mathrm{m} / z$ 444.37 $\left(\mathrm{M}+\mathrm{Na}^{+}\right)$, calculated for $\mathrm{C}_{18} \mathrm{H}_{35} \mathrm{~N}_{3} \mathrm{O}_{8}$ 444.24.

Compound 16. A solution of the azide $15(0.269 \mathrm{~g}, 0.639 \mathrm{mmol})$ in $5 \mathrm{~mL}$ of dry THF was cooled to 0 ${ }^{\circ} \mathrm{C}$. To this solution $\mathrm{PPh}_{3}(0.218 \mathrm{~g}, 0.831 \mathrm{mmol})$ was added, after which the mixture was allowed to attain $\mathrm{rt}$ and stirred at $\mathrm{rt} / 12 \mathrm{~h}$. Then, $\mathrm{H}_{2} \mathrm{O}(0.030 \mathrm{~g}, 1.66 \mathrm{mmol})$ was added in order to hydrolyze the phosphorous adduct and stirring was continued for $10 \mathrm{~h}$ more. The reaction mixture was diluted with $\mathrm{H}_{2} \mathrm{O}(20 \mathrm{~mL})$ and the aqueous phase washed with toluene. Evaporation of the aqueous phase by azeotropic distillation with $\mathrm{EtOH}$ at $40{ }^{\circ} \mathrm{C}$ gave the corresponding amine as a pale yellow oil in $80 \%$ yield, (0.202g). HPLC Solvent System 8: $t_{r}=10.53 \mathrm{~min} .{ }^{1} \mathrm{H}$ NMR $\left(\mathrm{CDCl}_{3}, 250 \mathrm{MHz}\right): \delta 3.88(2 \mathrm{H}, \mathrm{s})$, 3.51-3.55 (20H, m), $3.37(2 \mathrm{H}, \mathrm{t}, J=6.2 \mathrm{~Hz}), 2.71(2 \mathrm{H}, \mathrm{t}, J=6.2 \mathrm{~Hz}), 1.74(2 \mathrm{H}, \mathrm{s}), 1.33(9 \mathrm{H}, \mathrm{s}) .{ }^{13} \mathrm{C}$ NMR $\left(\mathrm{CDCl}_{3}, 62.5 \mathrm{MHz}\right): \delta 73.29,73.12,70.89,70.83,70.74,70.47,70.34,61.60,41.61 . \mathrm{LRMS}$ (ESI) $m / z 396.37\left(\mathrm{M}+\mathrm{H}^{+}\right)$, calculated for $\mathrm{C}_{18} \mathrm{H}_{38} \mathrm{NO}_{8} 396.25$. 


\section{Spectra}

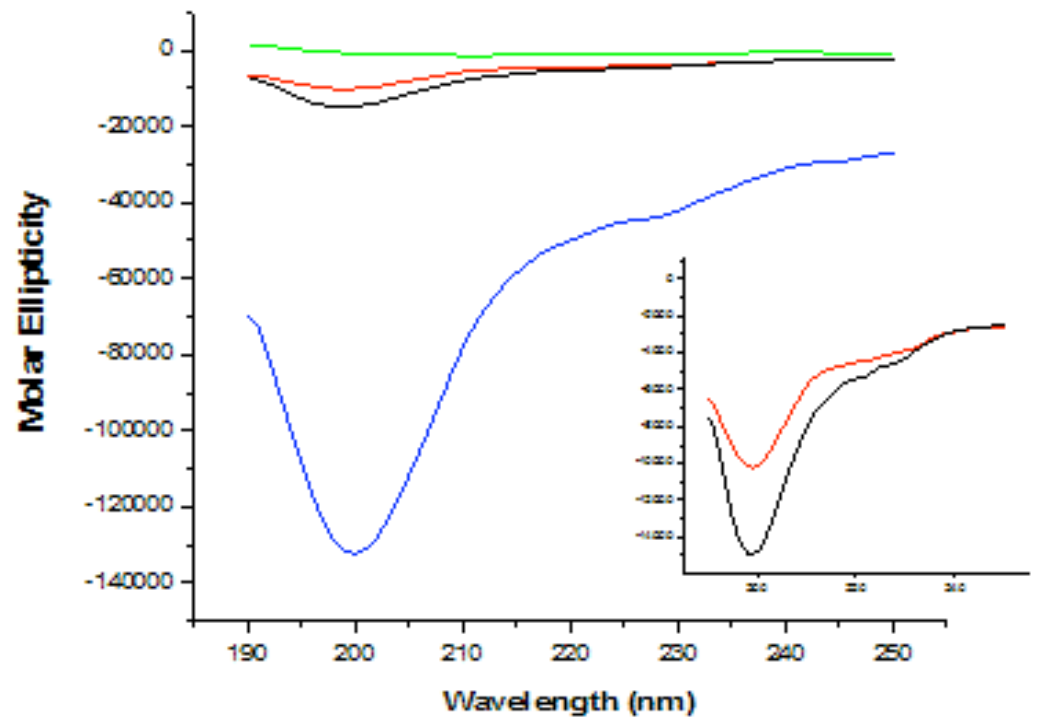

Figure S1. CD spectra amide region of conjugates 4 (black), 5 (red), 6 (blue) and porphyrin $\mathbf{3}$ (green) as reference, at $50 \mu \mathrm{M}$ in $10 \mathrm{mM}$ pH 7.5 TRIS buffer/TFE 80/20.

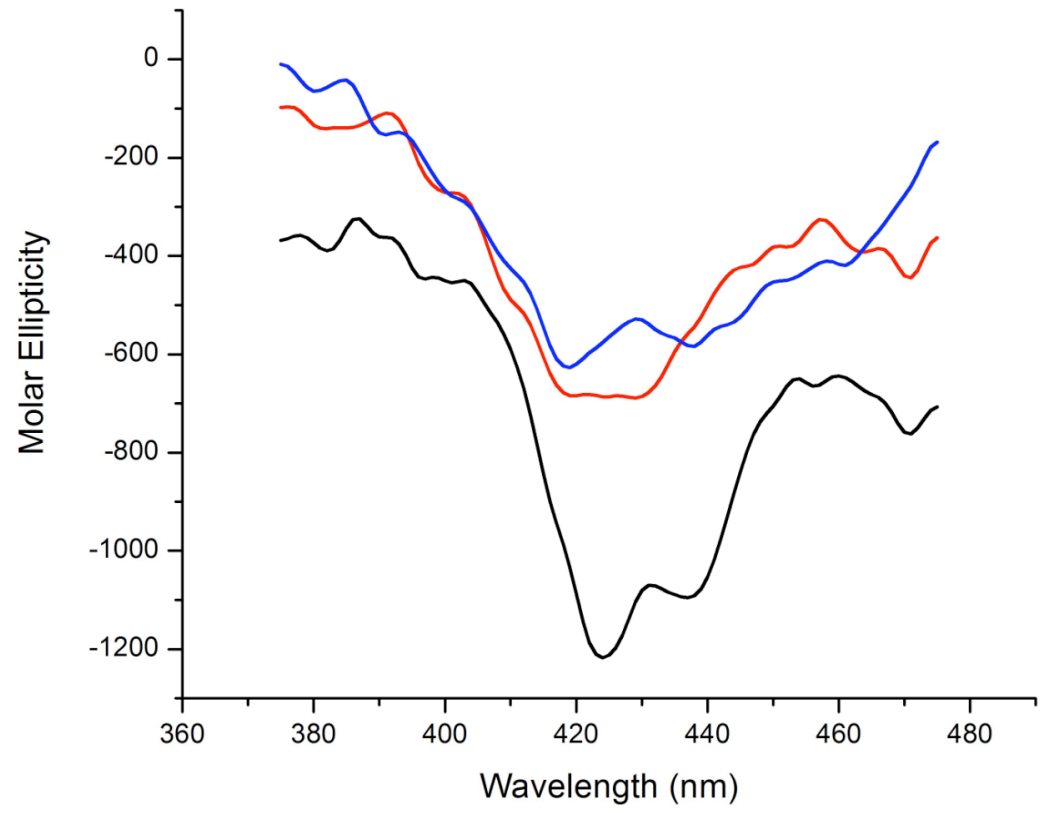

Figure S2. CD spectra Soret region of conjugates 4 (black), 5 (red) and 6 (blue), at $50 \mu \mathrm{M}$ in $10 \mathrm{mM} \mathrm{pH}$ 7.5 TRIS buffer/TFE 80/20. 


\section{Semi-preparative HPLC Conditions:}

General: Column: Luna $C_{18} 100 \AA, 5 \mu \mathrm{m}, 10 \times 250 \mathrm{~mm}$ (Phenomenex, USA) $150 \mathrm{~mm}$ (Waters, USA); flow rate $4 \mathrm{~mL} / \mathrm{min}$; injected volume $500 \mu \mathrm{L}$; wavelength detection: $400 \mathrm{~nm}$ and $210 \mathrm{~nm}$.

Solvent system 1 (Conjugates 4-6): stepwise gradient from $40 \%$ to $95 \%$ buffer B. Buffer A: $5 \%$ acetonitrile, $0.1 \%$ TFA, $\mathrm{H}_{2} \mathrm{O}$. Buffer B: $5 \% \mathrm{H}_{2} \mathrm{O}, 0.1 \%$ TFA, acetonitrile

Solvent System 2 (Conjugates 10-11): stepwise gradient $20 \%$ to $95 \%$ buffer B. Buffer A: 5\% acetonitrile, $0.1 \%$ TFA, $\mathrm{H}_{2} \mathrm{O}$. Buffer B: $5 \% \mathrm{H}_{2} \mathrm{O}, 0.1 \%$ TFA, acetonitrile

\section{Analytical HPLC conditions:}

General: Column: Delta Pak $C_{18} 300 \AA$, $5 \mu \mathrm{m}, 3.9$ x $150 \mathrm{~mm}$ (Waters, USA); flow rate $1 \mathrm{~mL} / \mathrm{min}$; injected volume $20 \mu \mathrm{L}$; wavelength detection: $420 \mathrm{~nm}$.

Solvent system 1: stepwise gradient from $40 \%$ to $95 \%$ buffer B. Buffer A: 5\% acetonitrile, $0.1 \%$ TFA, $\mathrm{H}_{2} \mathrm{O}$. Buffer B: $5 \% \mathrm{H}_{2} \mathrm{O}, 0.1 \%$ TFA, acetonitrile

Solvent system 2: $10 \mathrm{mM}$ phosphate buffer; $\mathrm{pH} 2.5$, acetonitrile; stepwise gradient $60 \%$ to $80 \%$ acetonitrile.

Solvent System 3: stepwise gradient $20 \%$ to $95 \%$ buffer B. Buffer A: 5\% acetonitrile, $0.1 \%$ TFA, $\mathrm{H}_{2} \mathrm{O}$. Buffer B: $5 \% \mathrm{H}_{2} \mathrm{O}, 0.1 \%$ TFA, acetonitrile

Solvent System 4: $10 \mathrm{mM}$ phosphate buffer; $\mathrm{pH} 2.5$, acetonitrile; stepwise gradient $30 \%$ to $80 \%$ acetonitrile.

Solvent System 5: isocratic conditions, acetonitrile.

Solvent System 6: stepwise gradient $80 \%$ to $95 \%$ buffer B. Buffer A: $5 \%$ acetonitrile, $0.1 \%$ TFA, $\mathrm{H}_{2} \mathrm{O}$. Buffer B: $5 \% \mathrm{H}_{2} \mathrm{O}, 0.1 \%$ TFA, acetonitrile.

Solvent System 7: stepwise gradient $70 \%$ to $95 \%$ buffer B. Buffer A: $5 \%$ acetonitrile, $0.1 \%$ TFA, $\mathrm{H}_{2} \mathrm{O}$. Buffer B: $5 \% \mathrm{H}_{2} \mathrm{O}, 0.1 \%$ TFA, acetonitrile.

Solvent System 8: wavelength detection: $230 \mathrm{~nm}$, isocratic conditions, $\mathrm{MeOH} /$ Water 50/50. $\mathbf{8}^{a}$ $\mathrm{MeOH} /$ Water 40/60. 


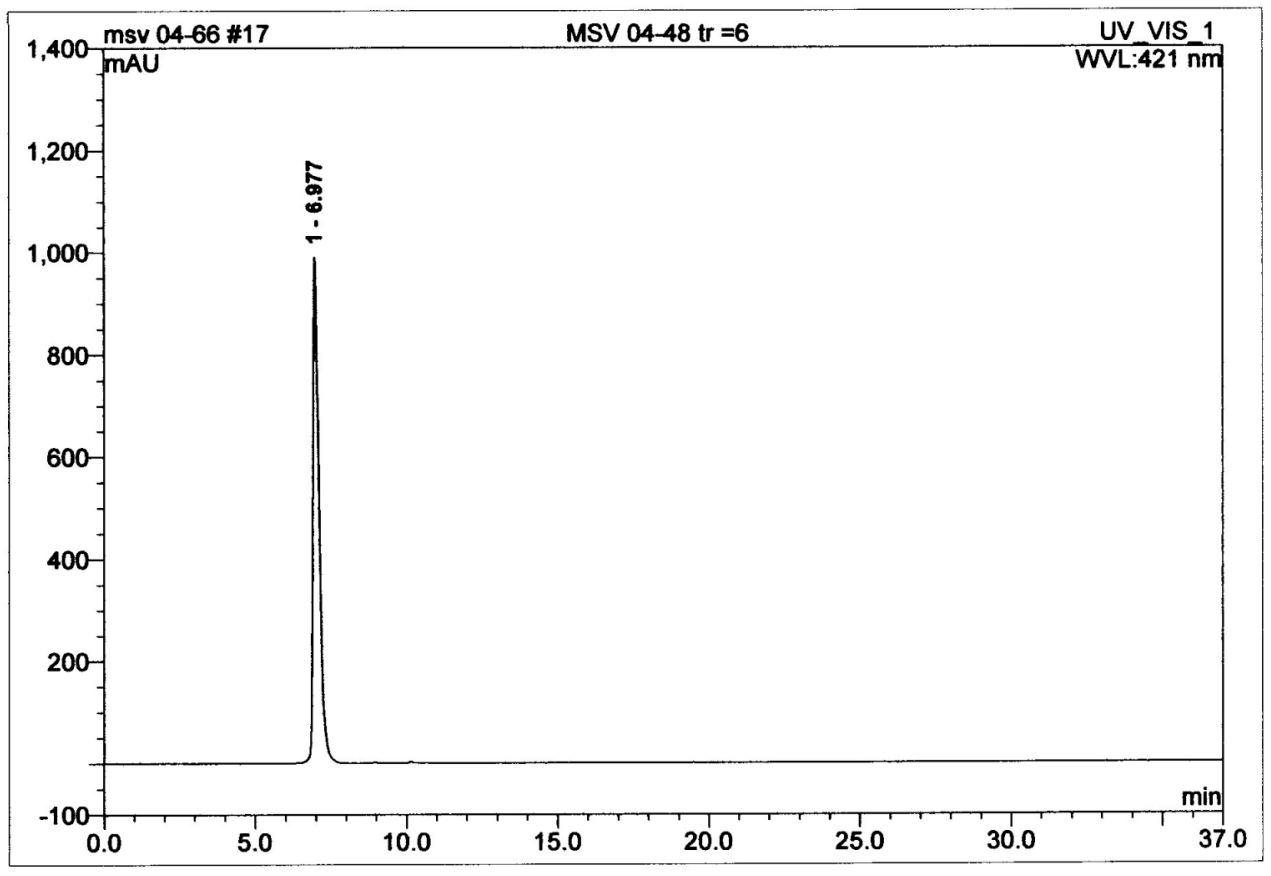

Figure S3. HPLC trace conjugate 4, solvent system 1.

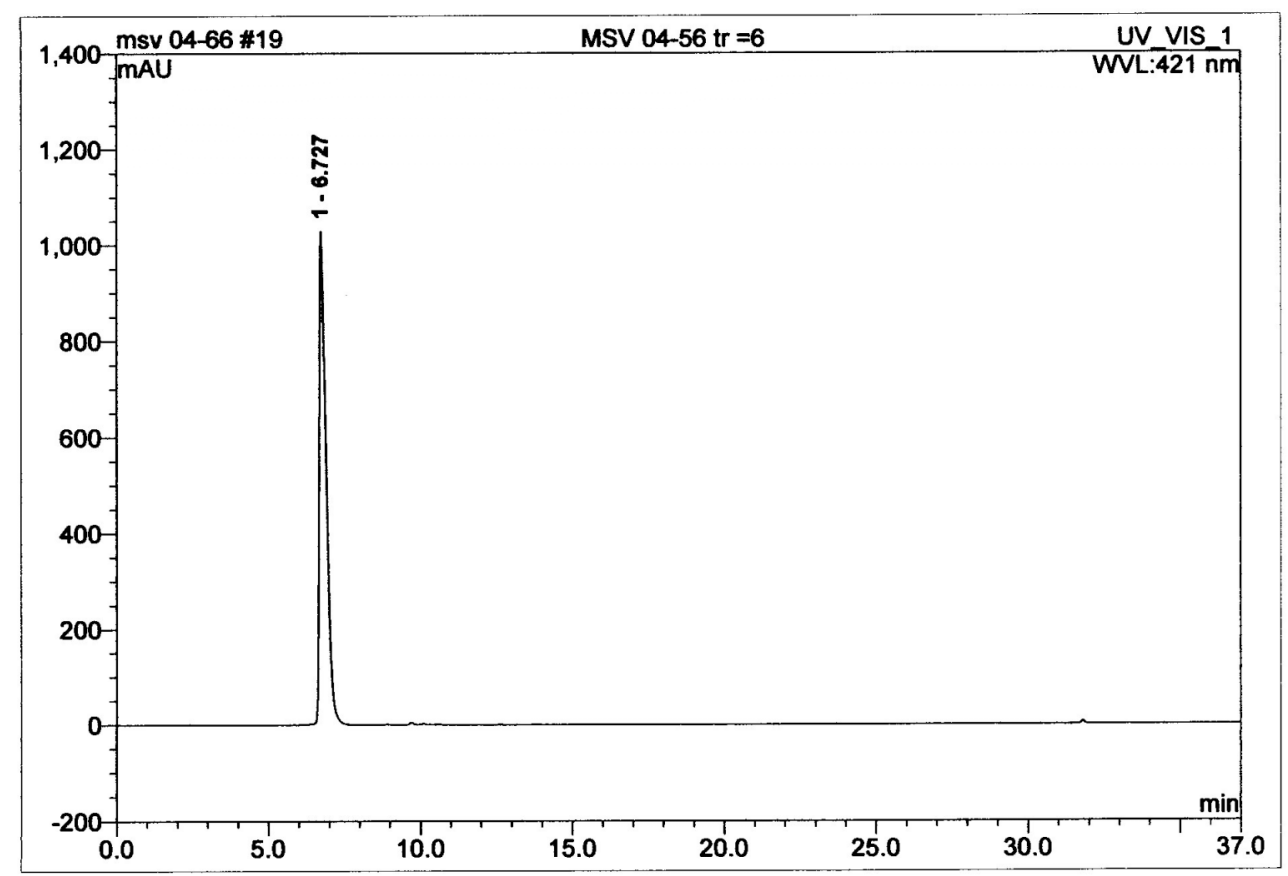

Figure S4. HPLC trace conjugate 5, solvent system 1. 


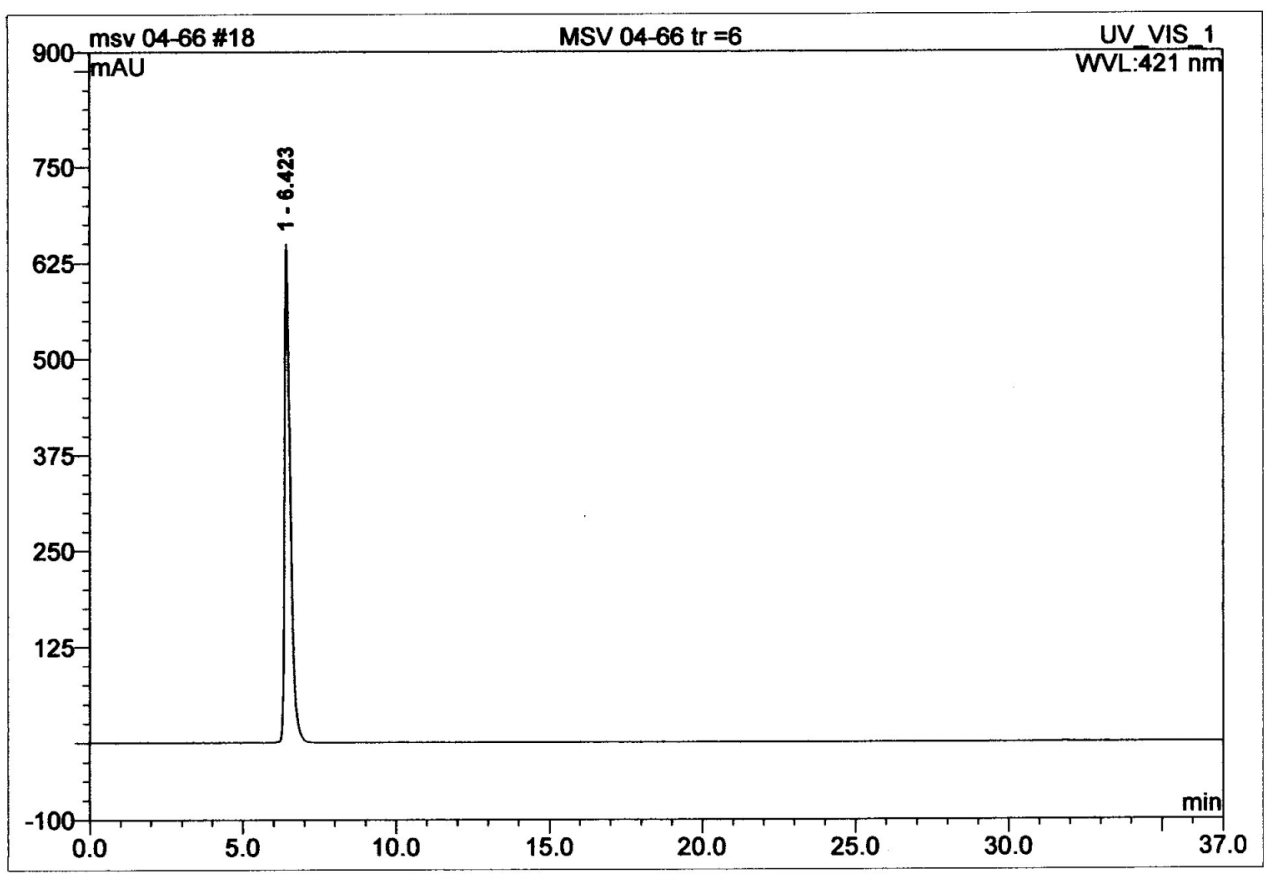

Figure S5. HPLC trace conjugate 6, solvent system 1. 


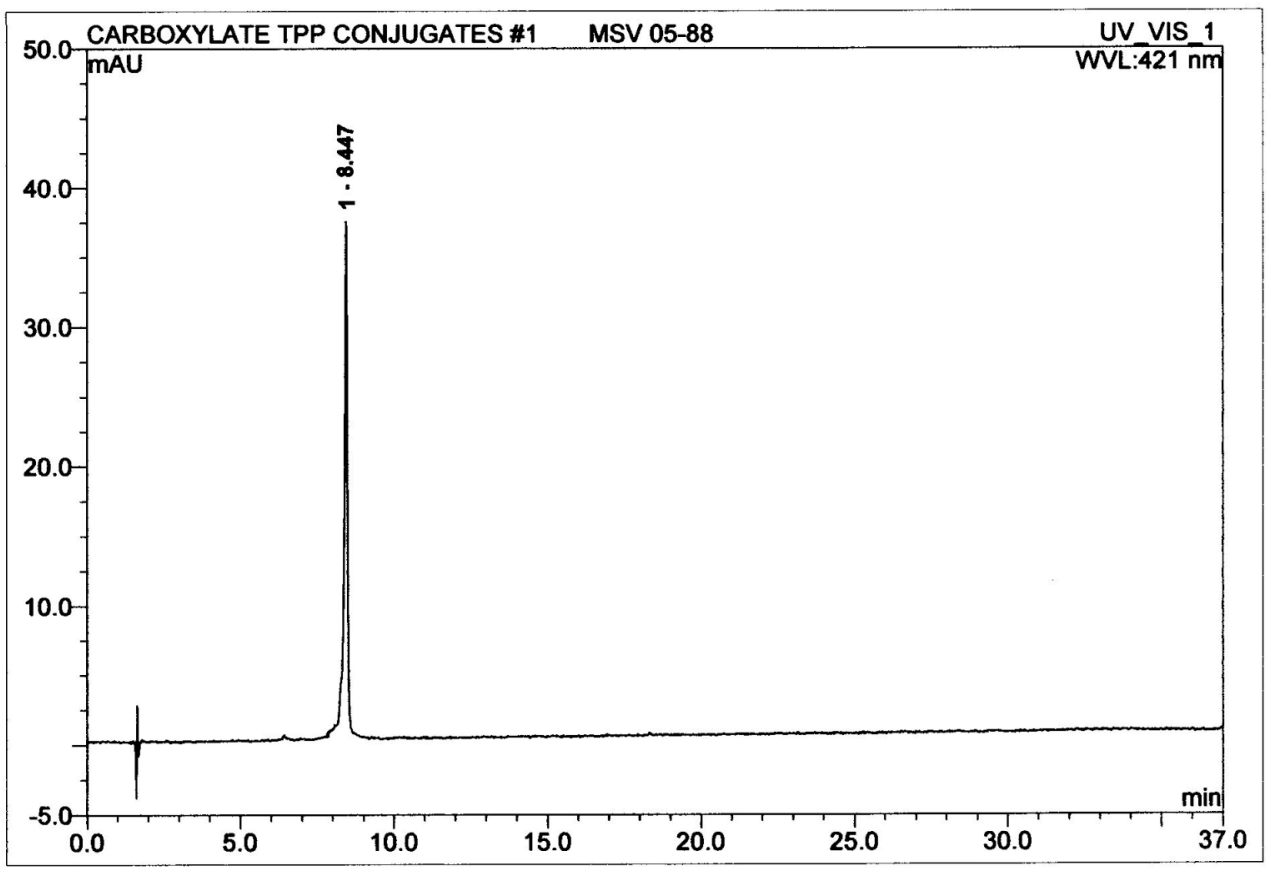

Figure S6. HPLC trace conjugate 10, Solvent system 3.

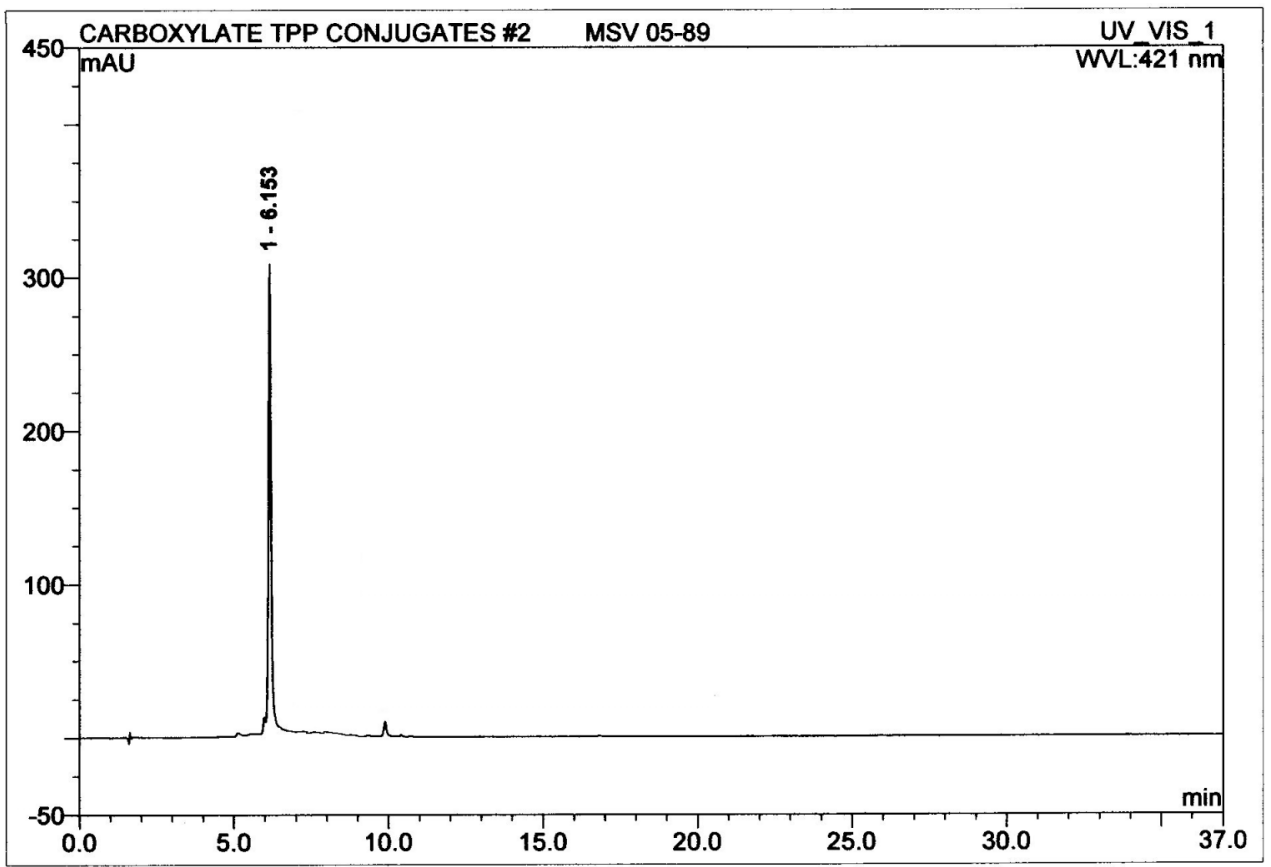

Figure S7. HPLC trace conjugate 11, Solvent system 3. 

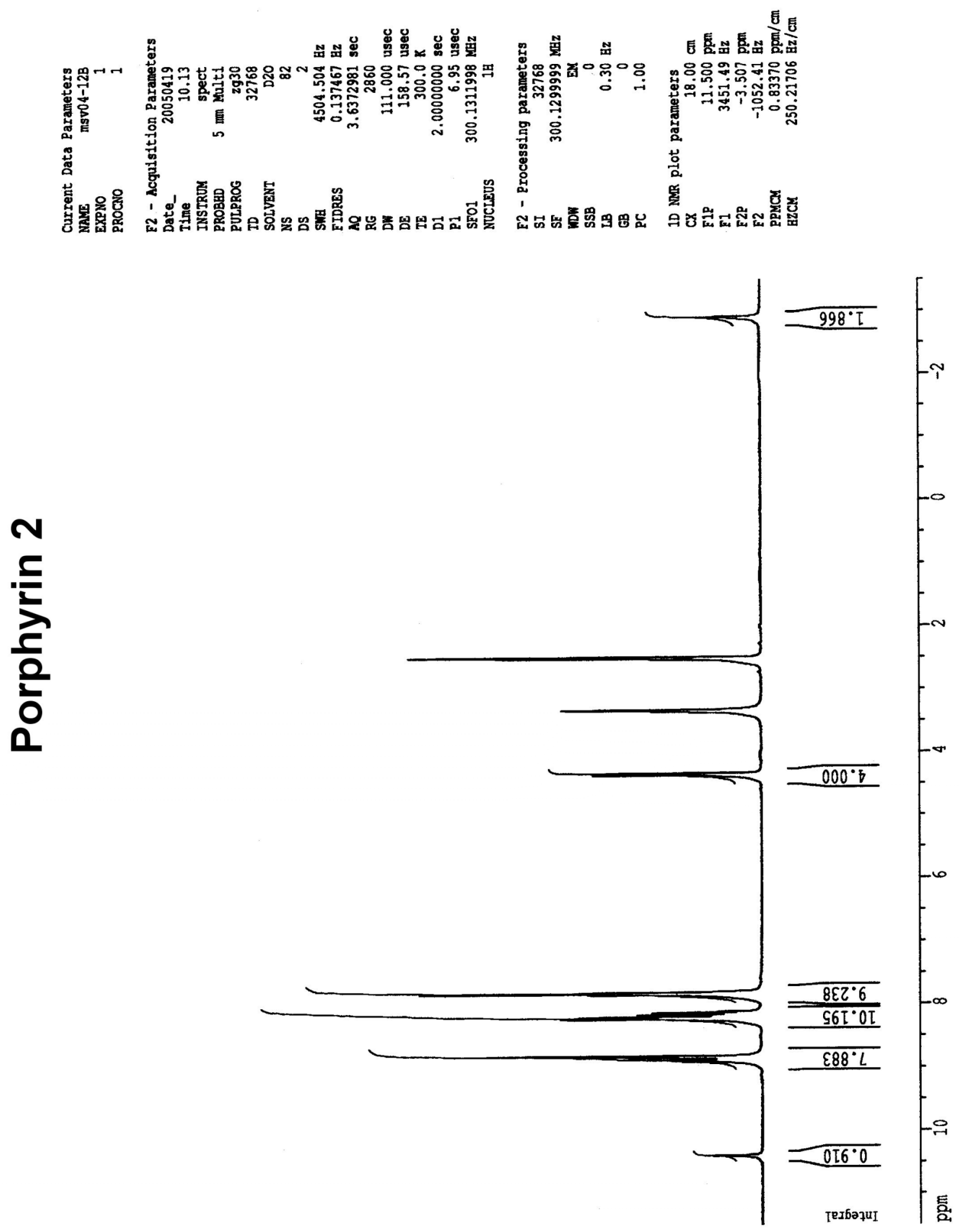


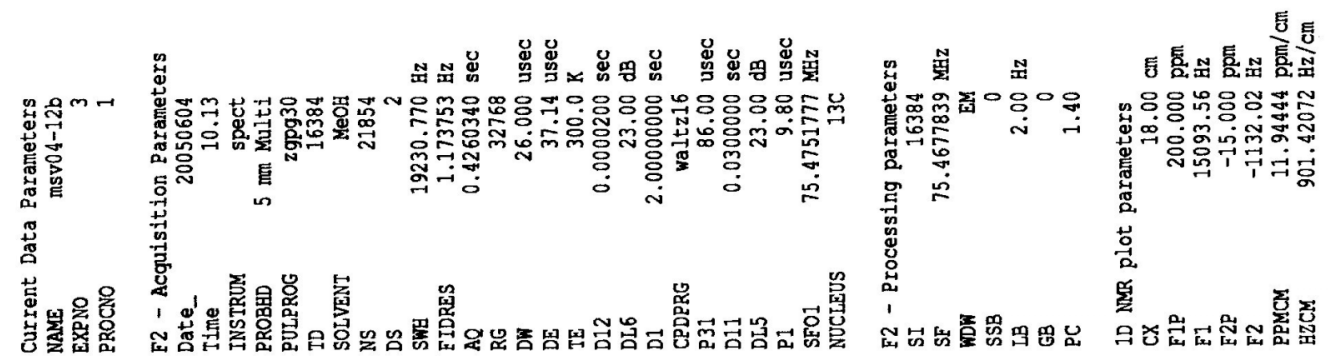

ำ

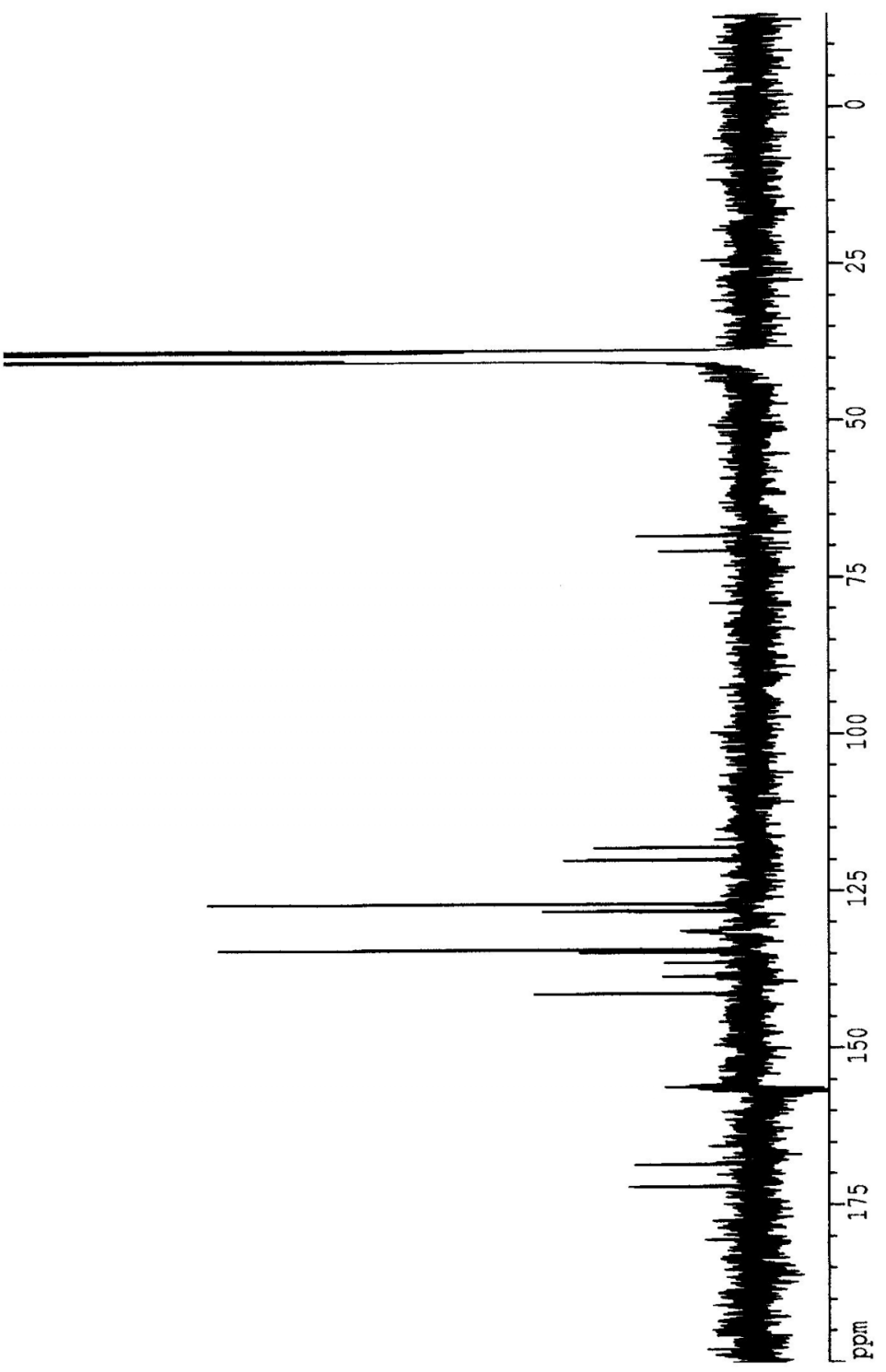



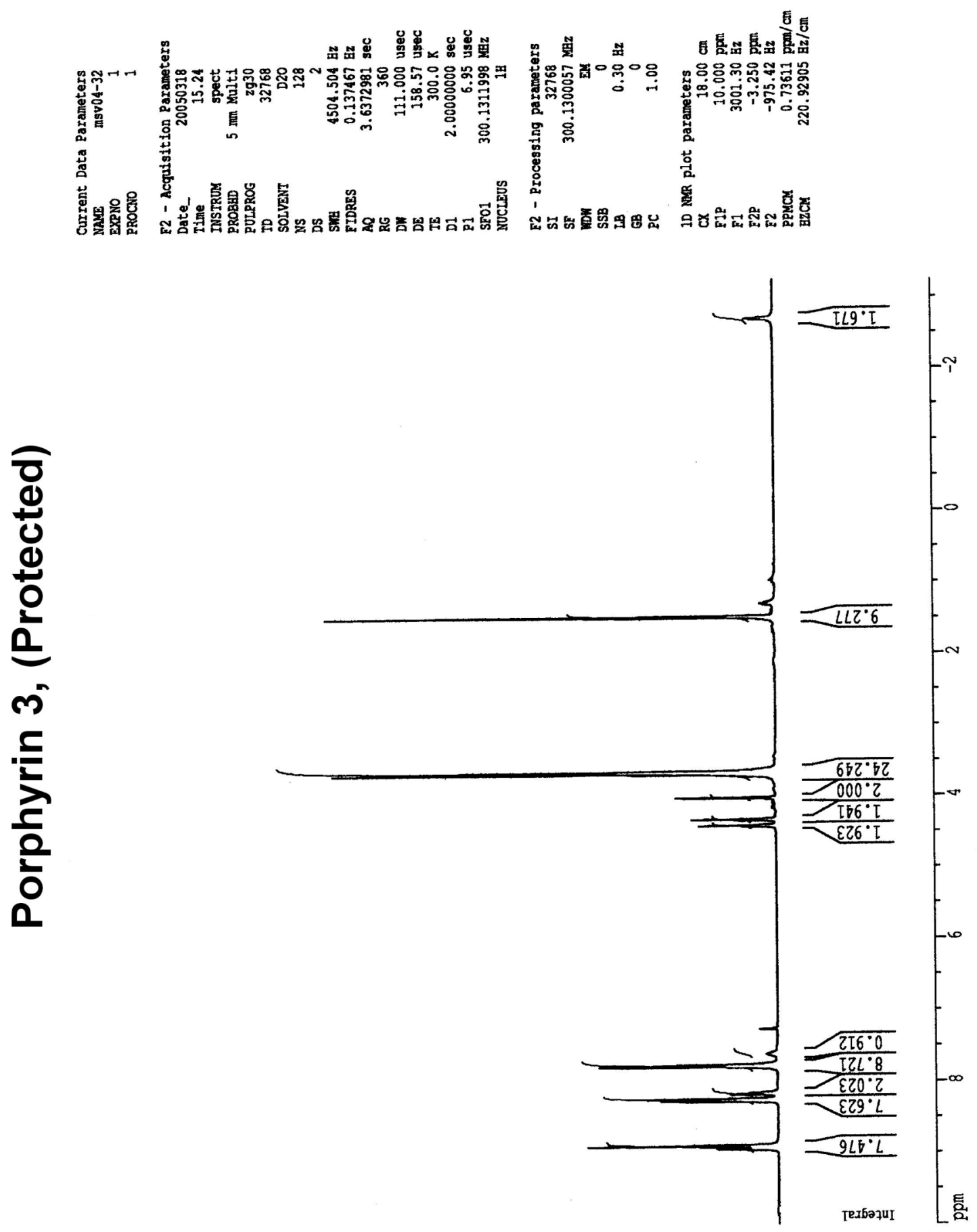

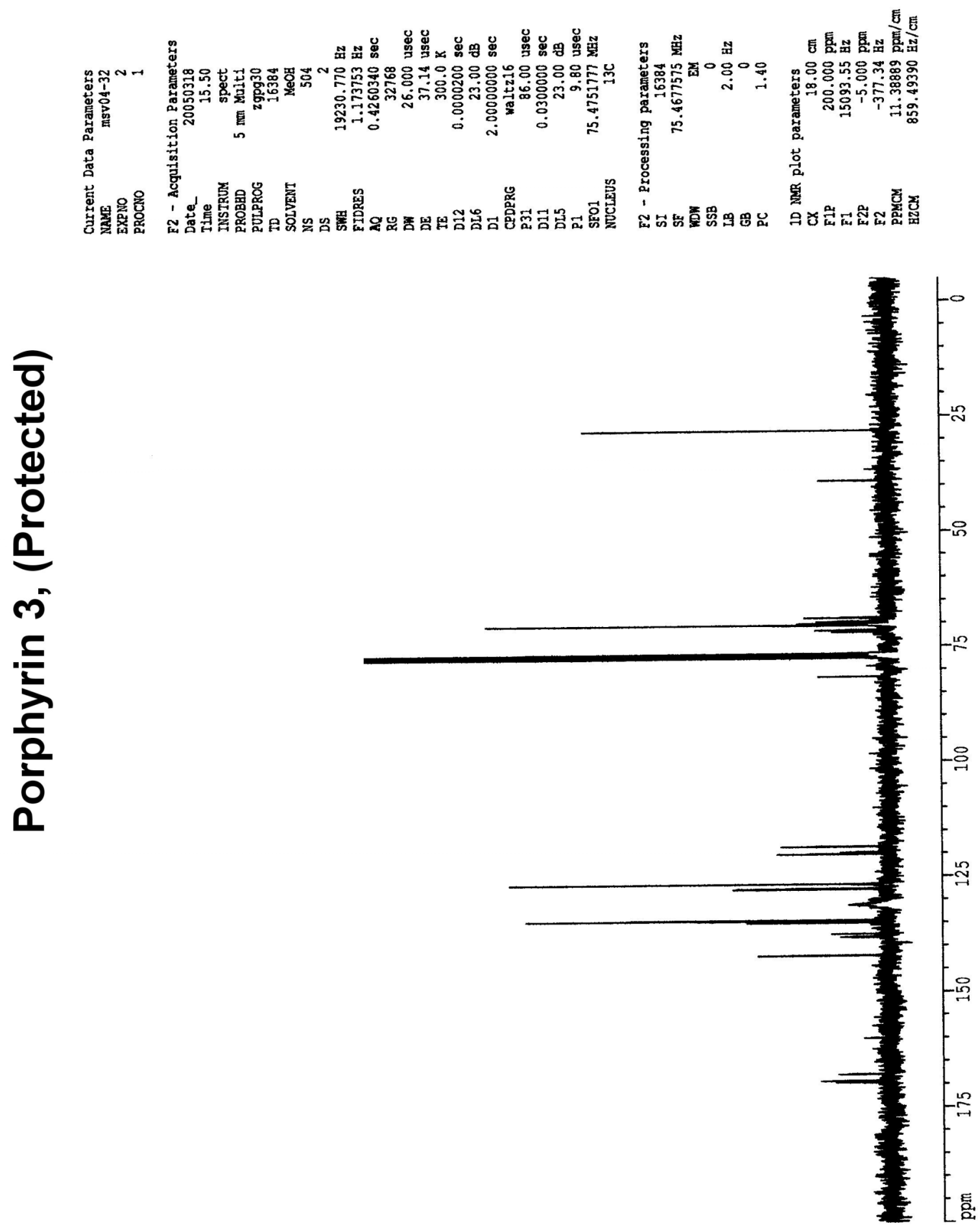

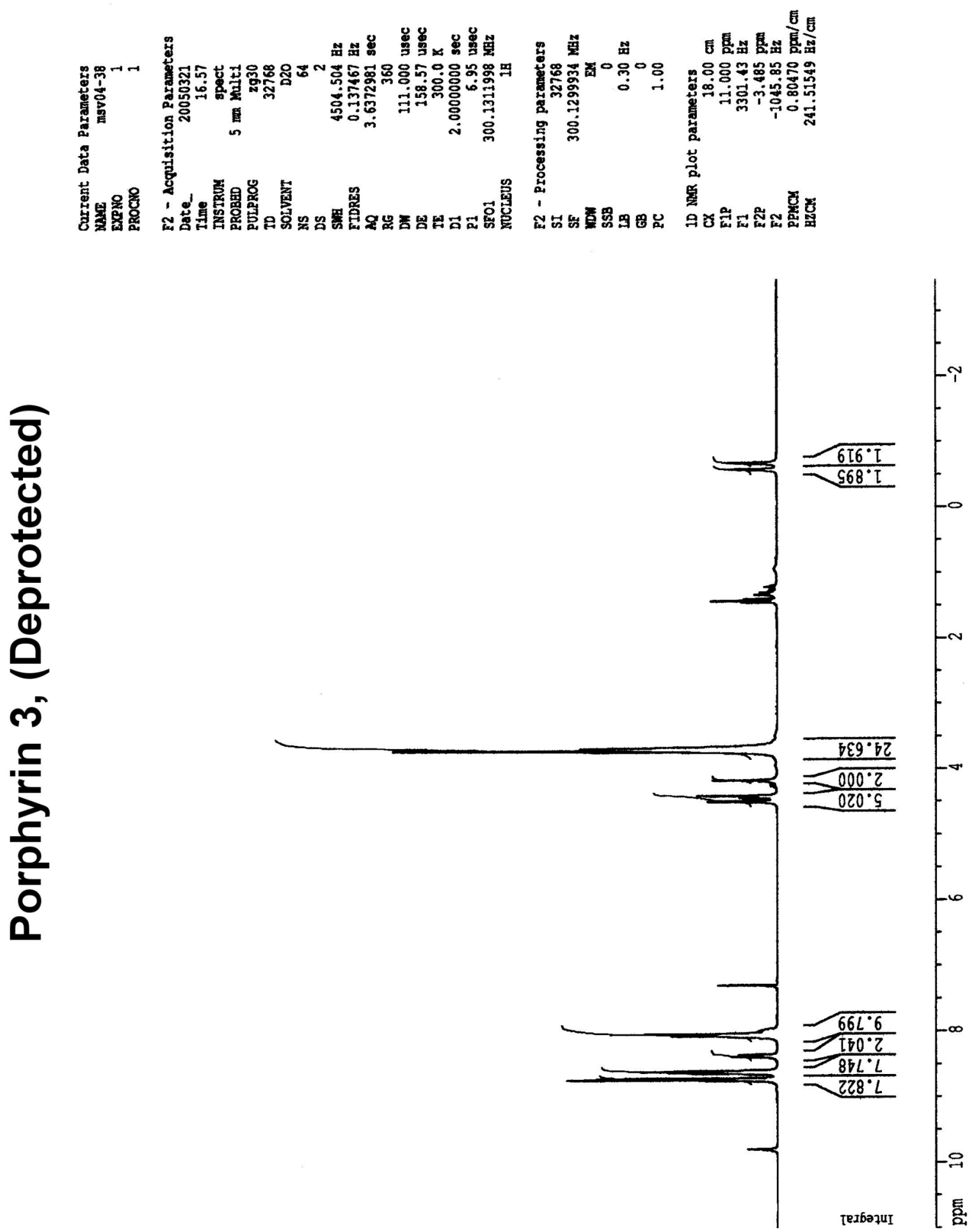

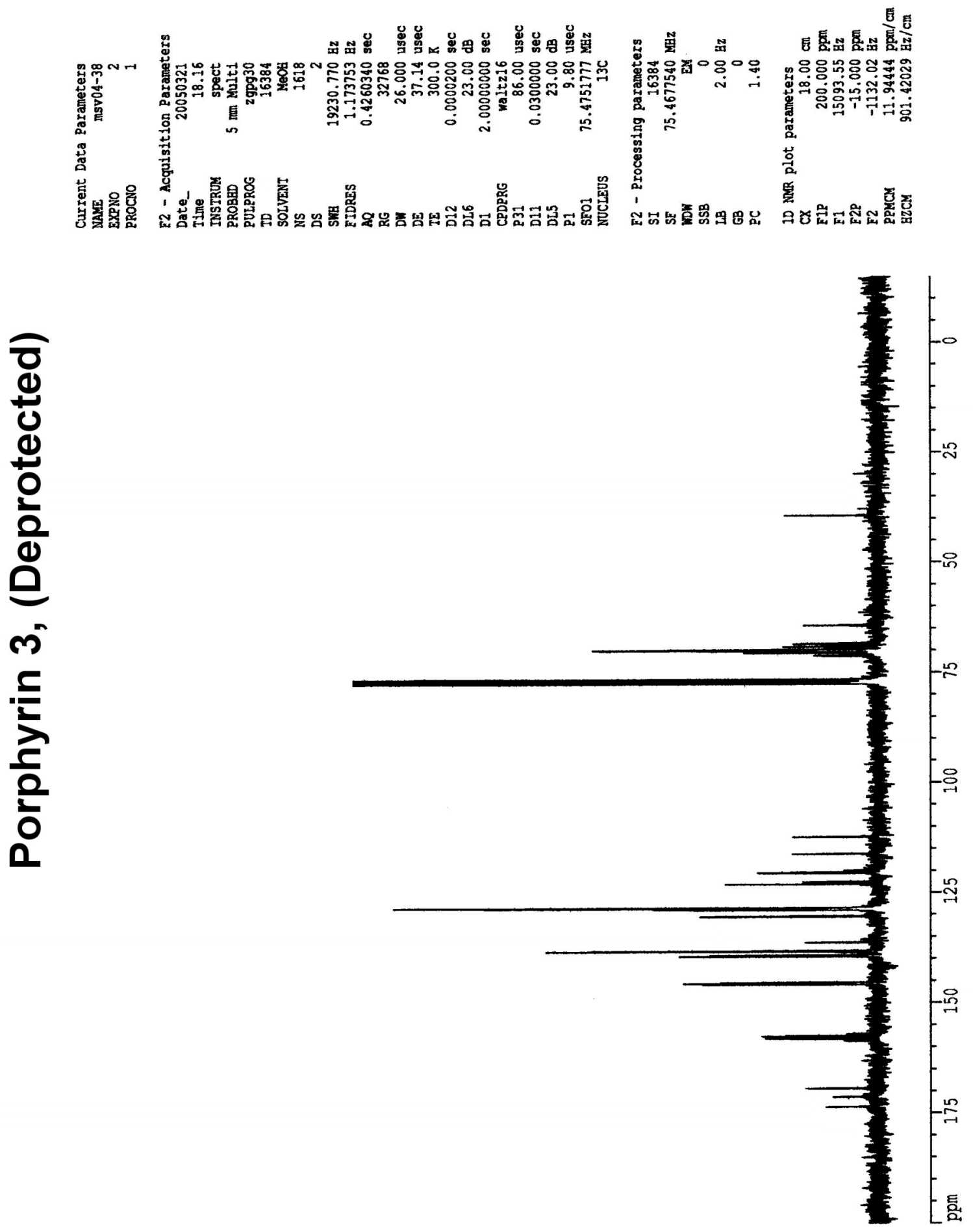

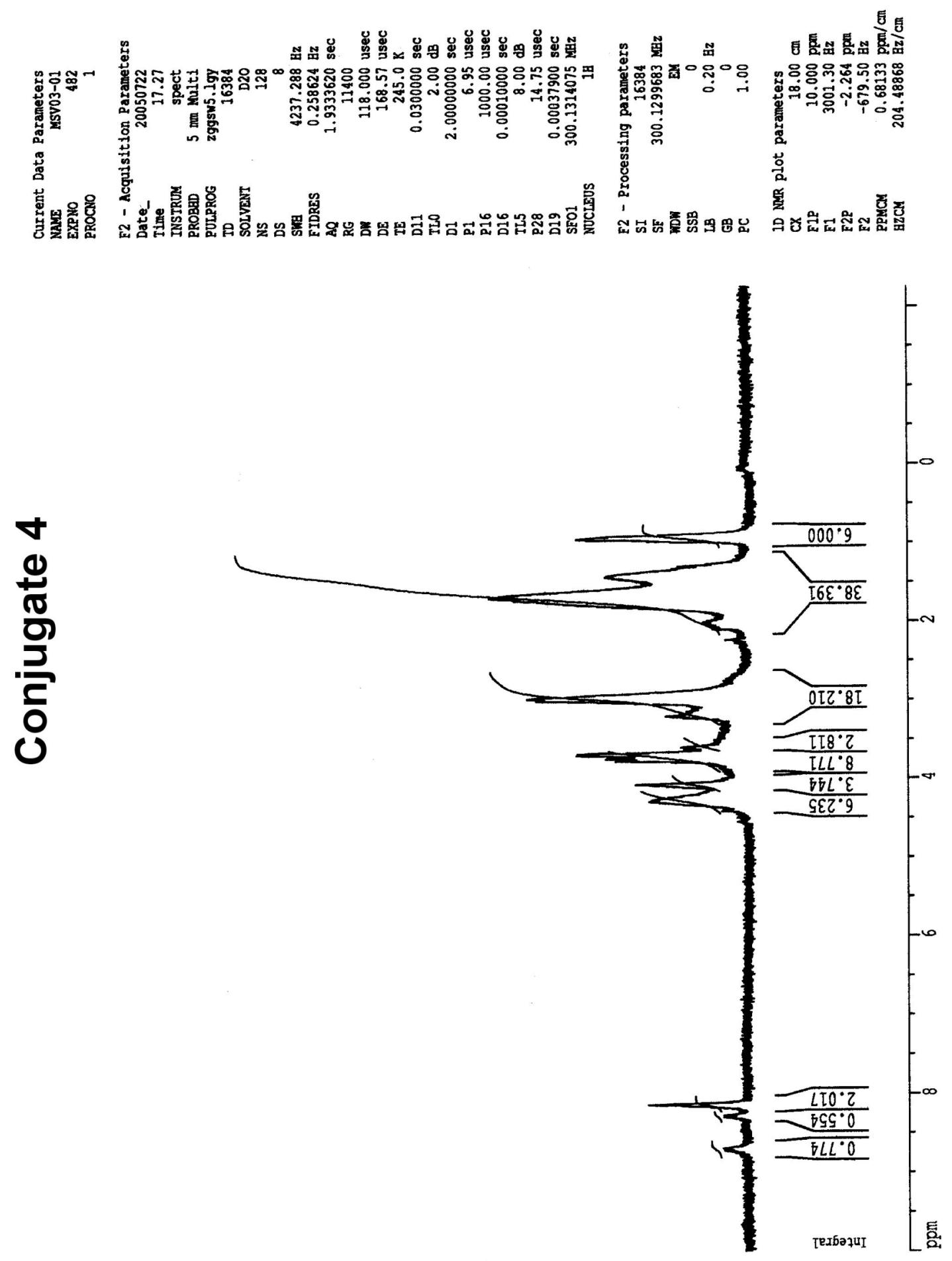

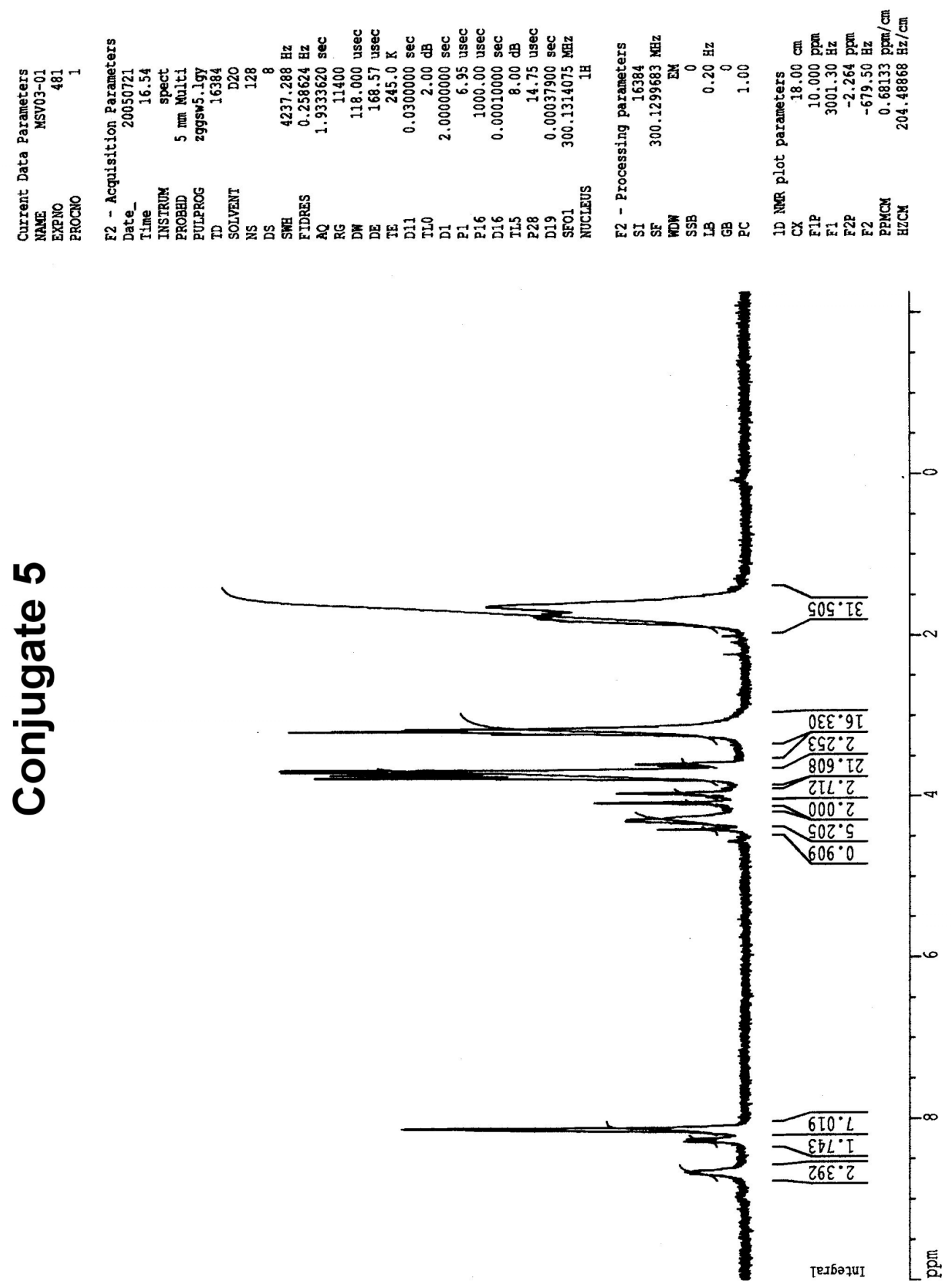

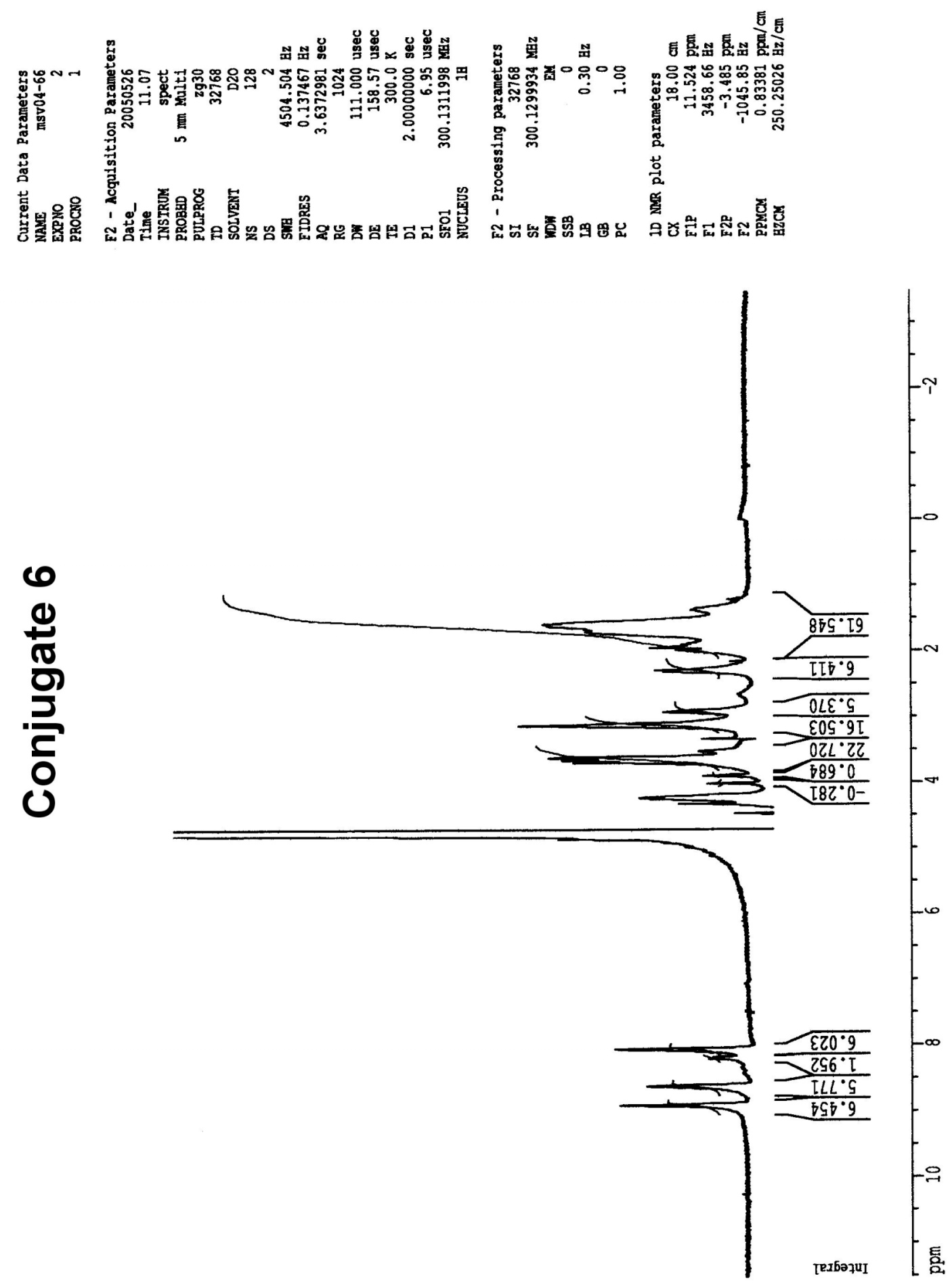

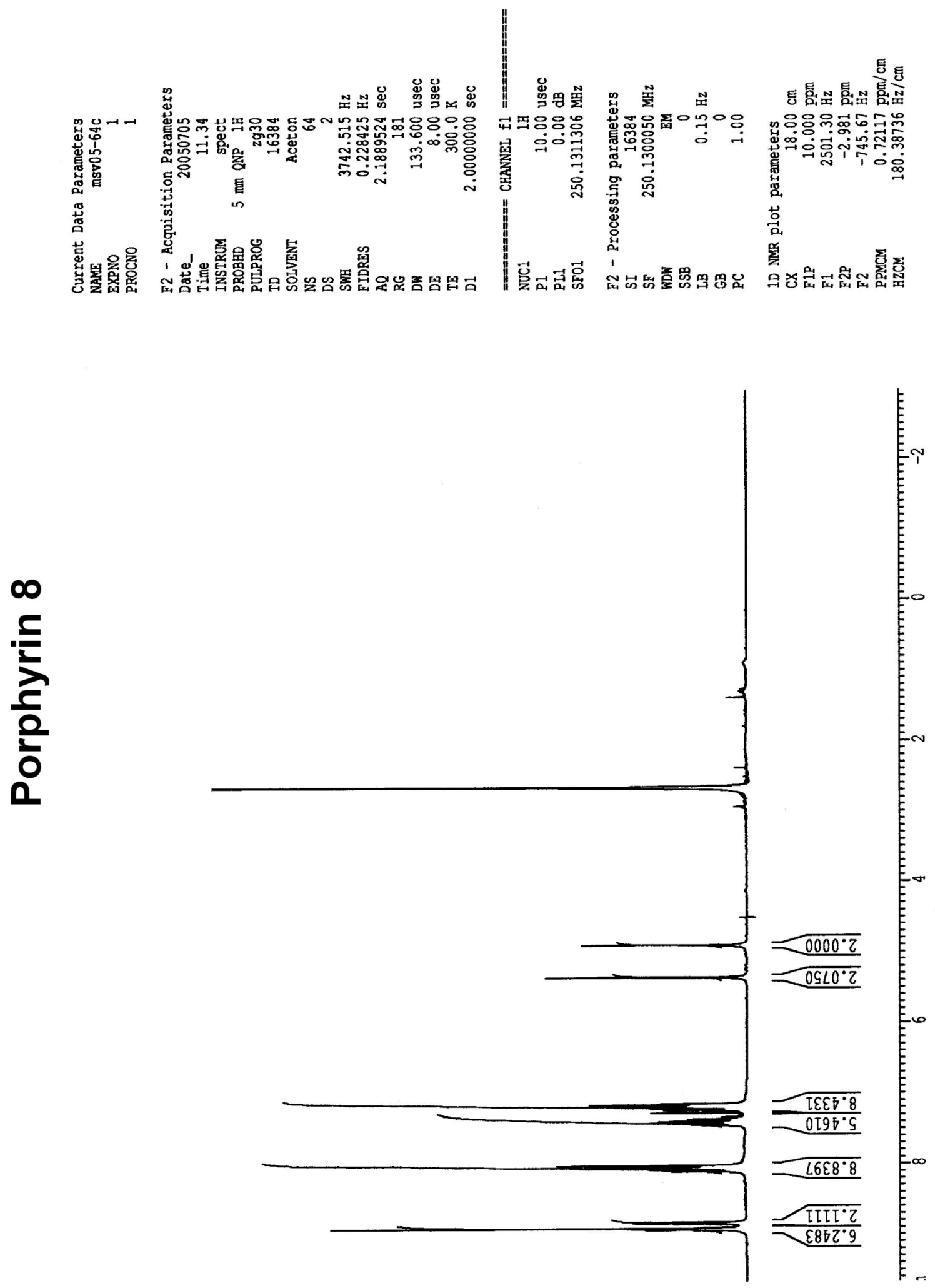

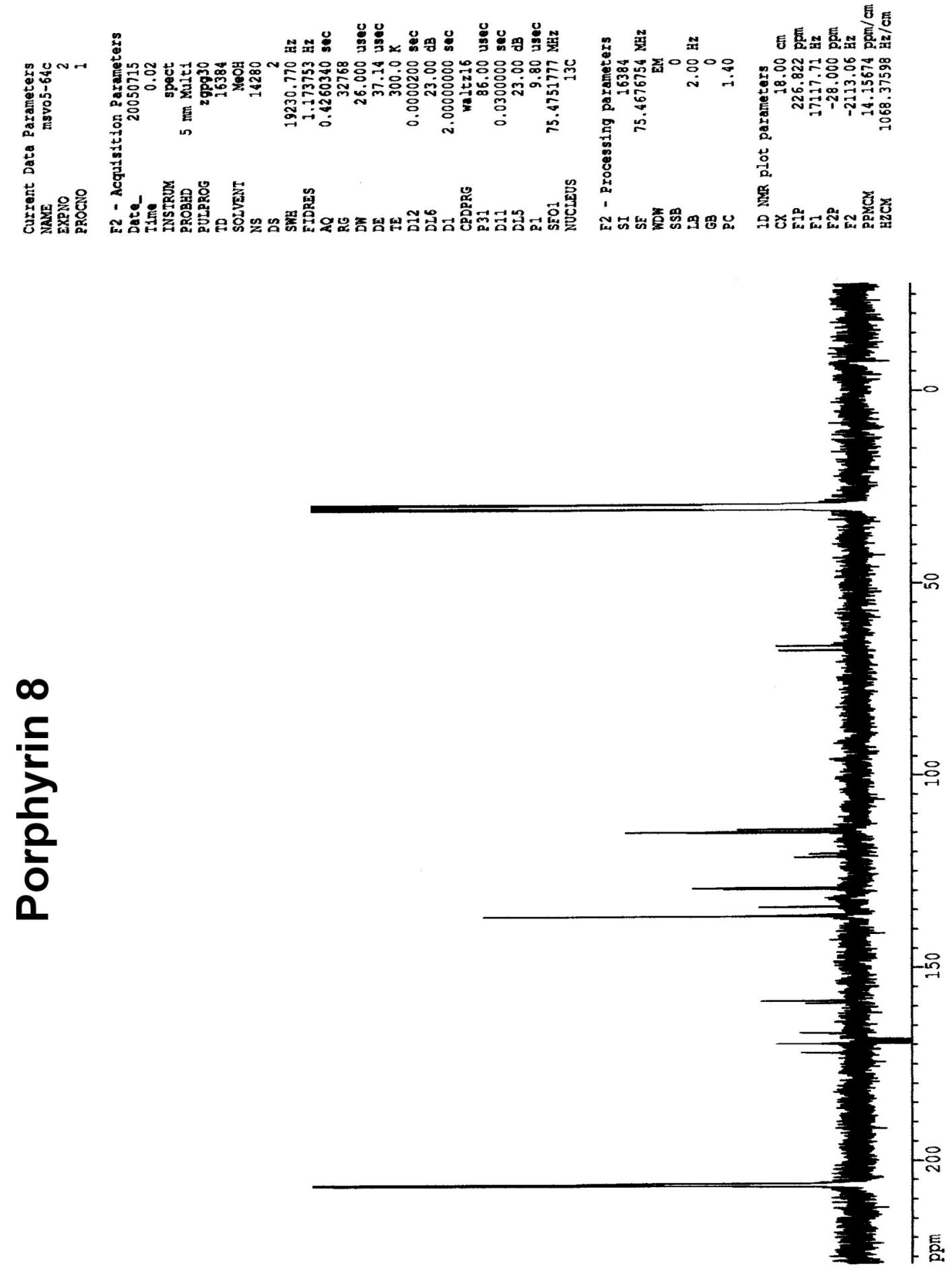

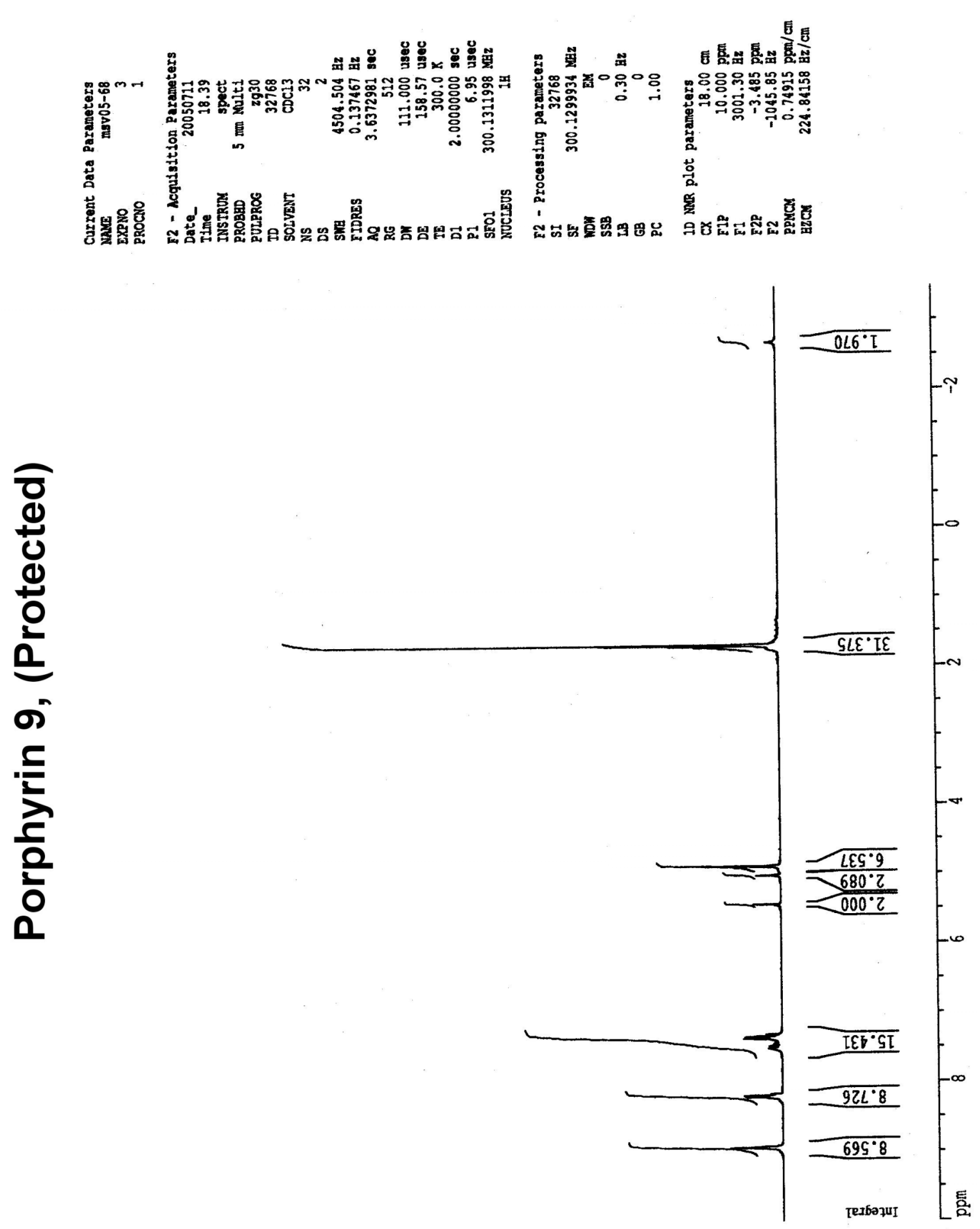

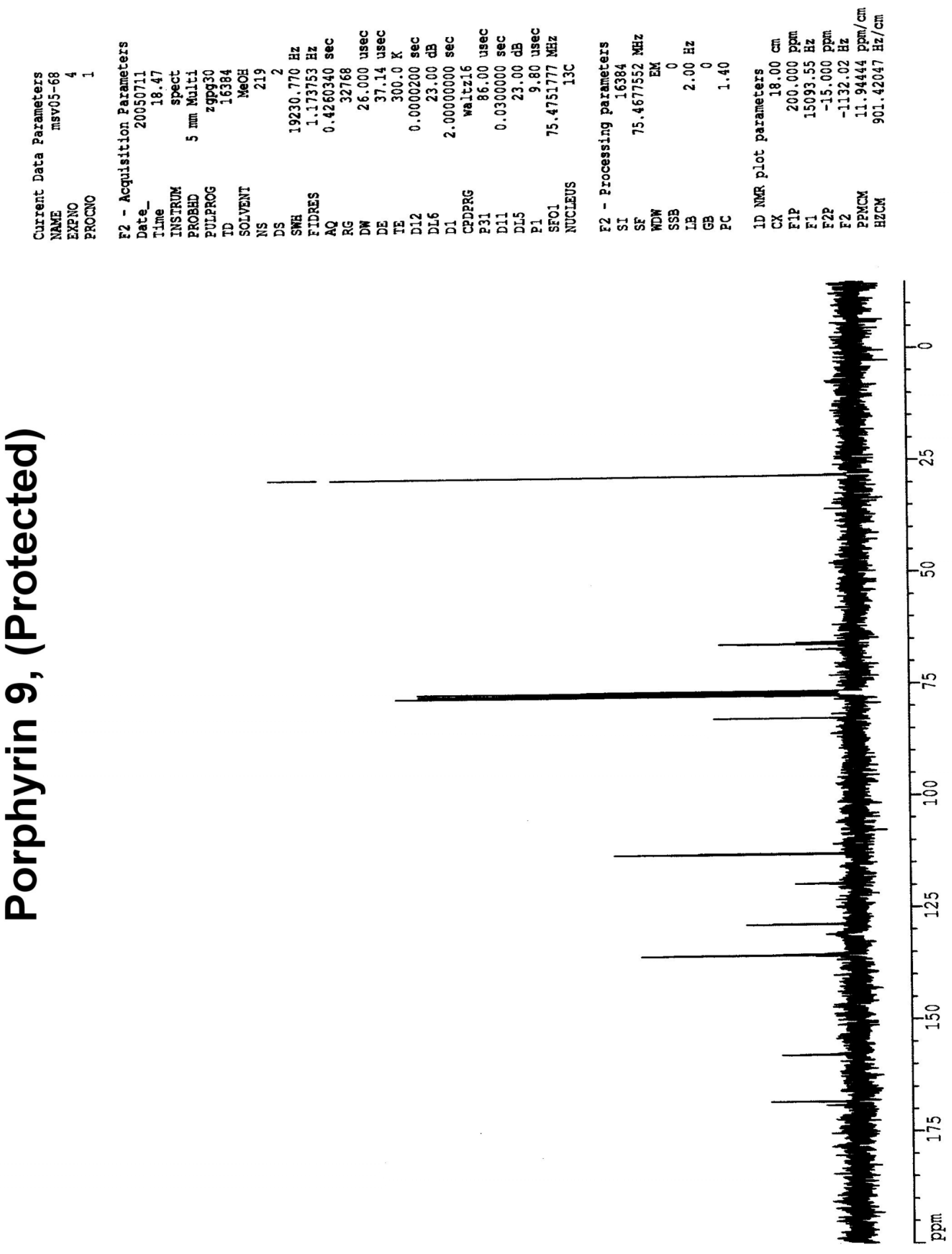

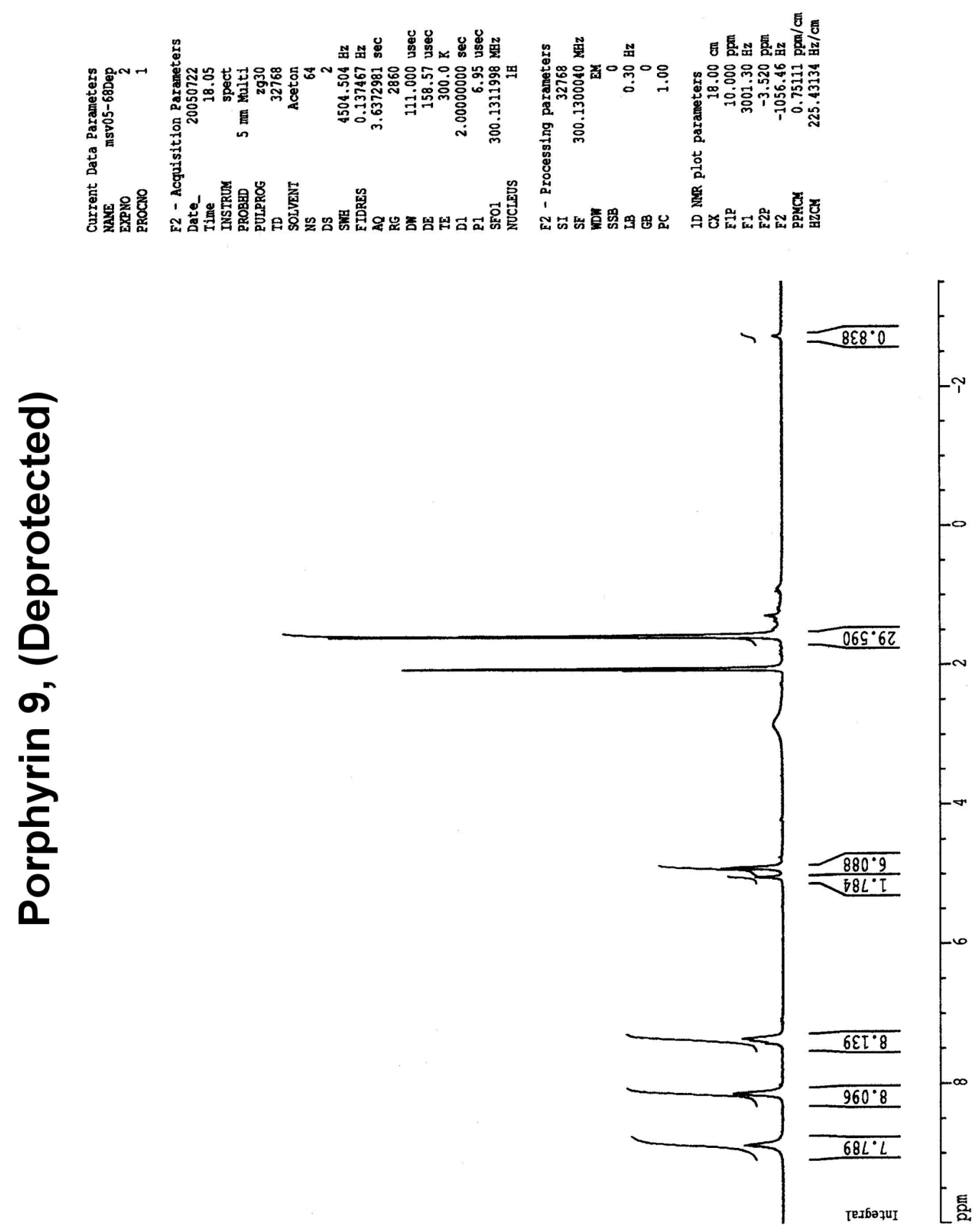

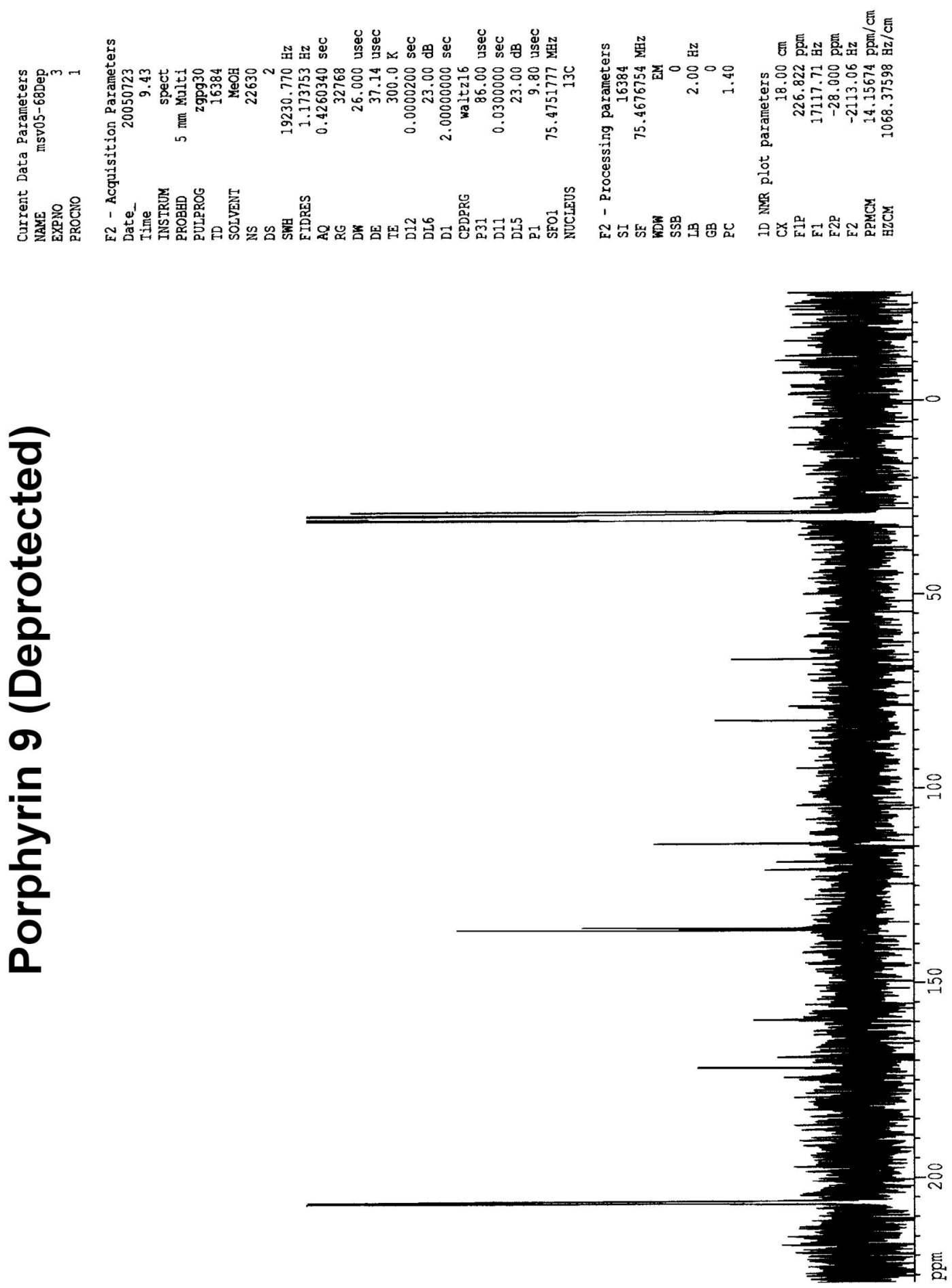

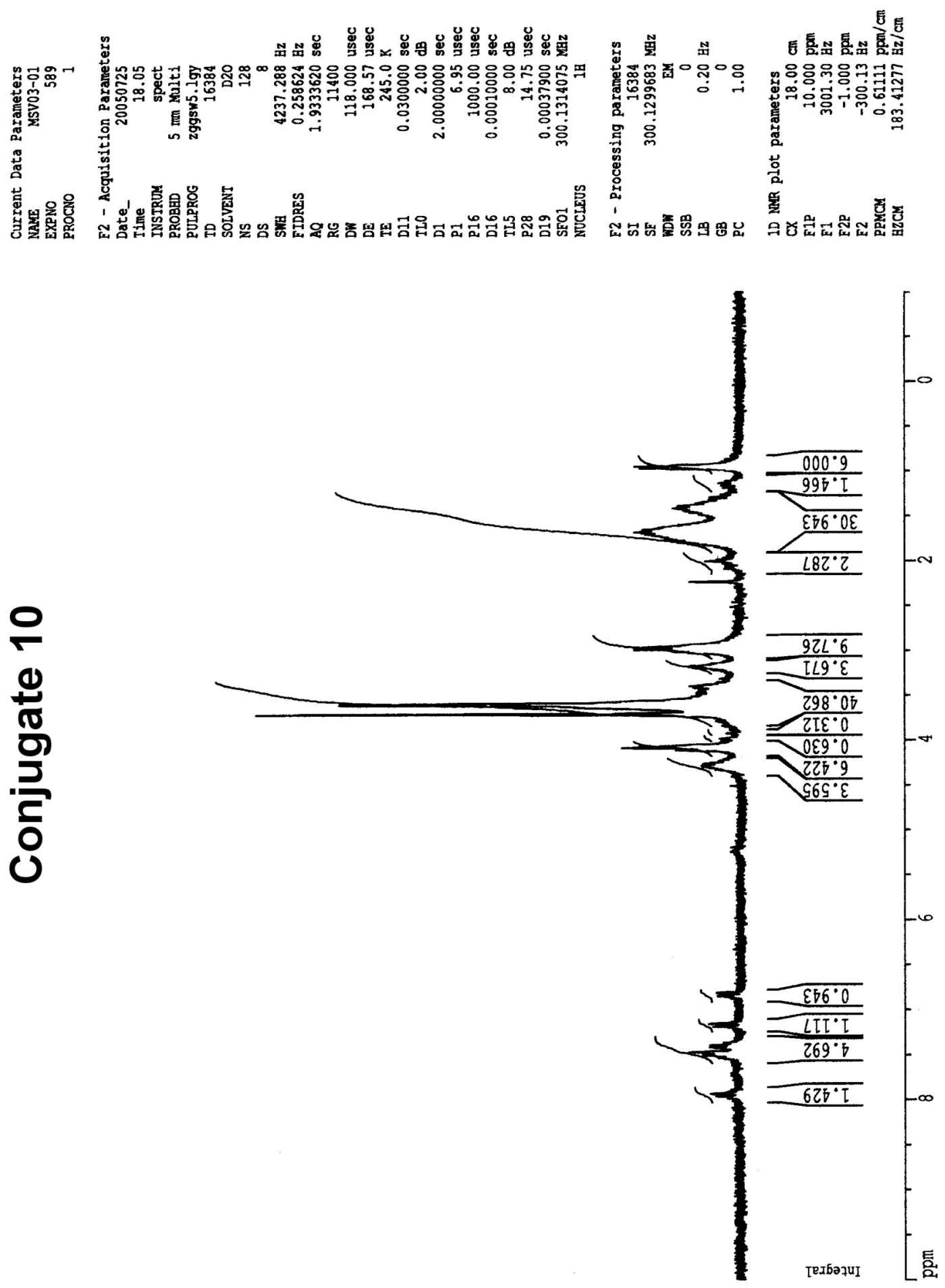

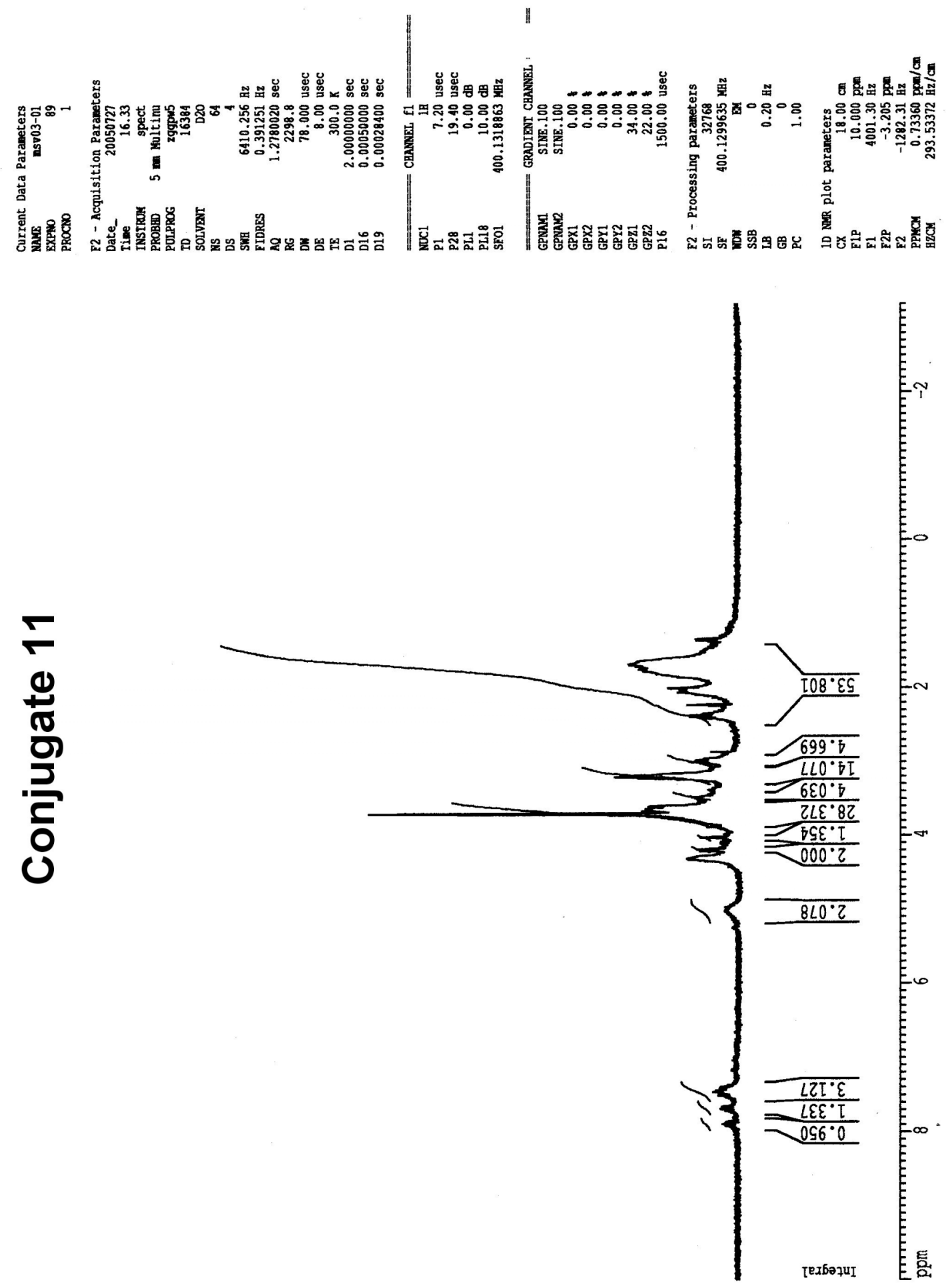
Intracellular localization for conjugates 5, 6 and 11
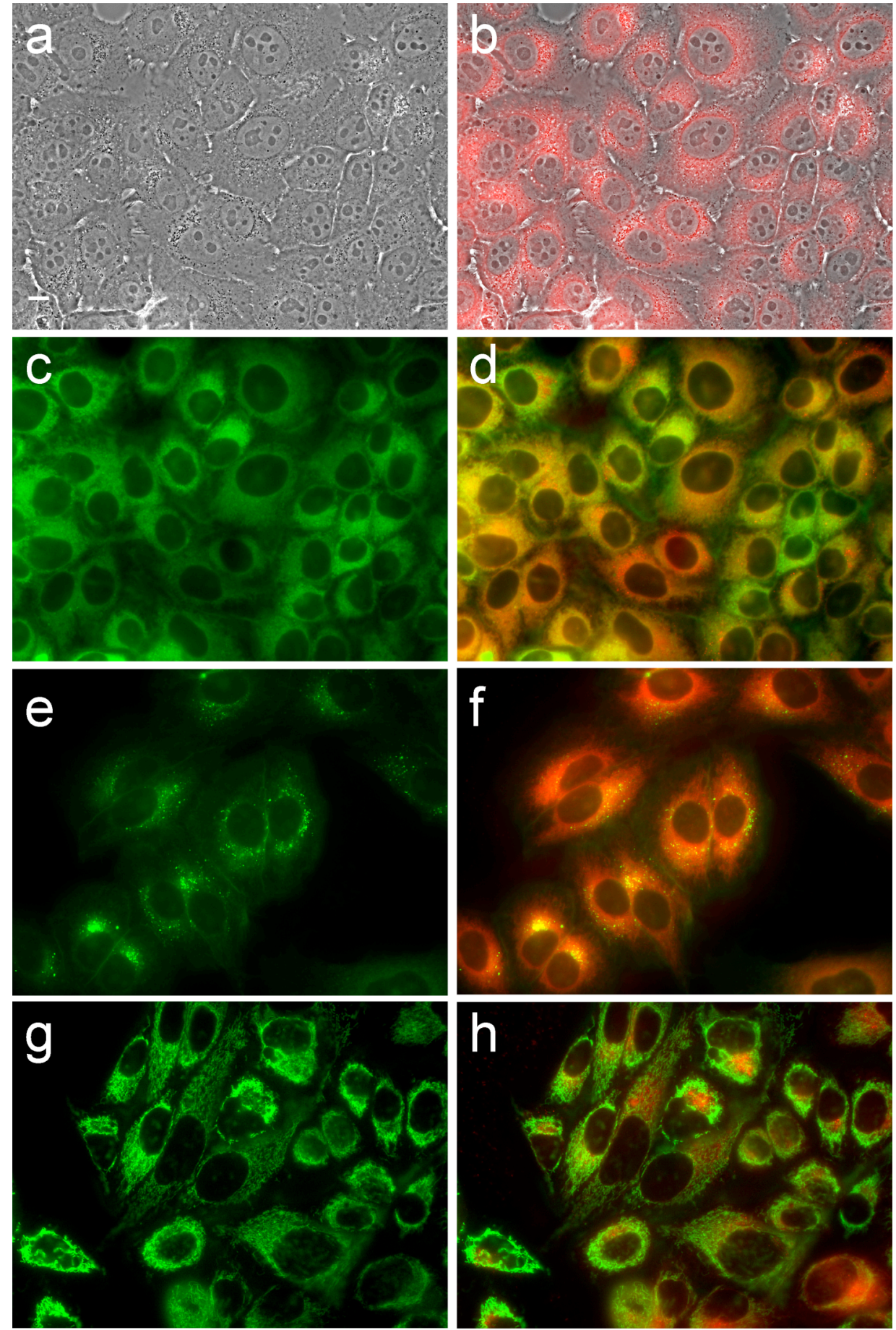

Figure S8. Subcellular localization of conjugate 5 in HEp2 cells at $10 \mu \mathrm{M}$ for $18 \mathrm{~h}$. (a) phase contrast, (b) overlay of 5 fluorescence and phase contrast, (c) $\mathrm{DiOC}_{6}$ fluorescence, (e) LysoSensor Green fluorescence, (g) MitoTracker Green fluorescence, (d), (f) (g) overlays of organelle tracers with 5 fluorescence. Scale bar: $10 \mu \mathrm{m}$. 

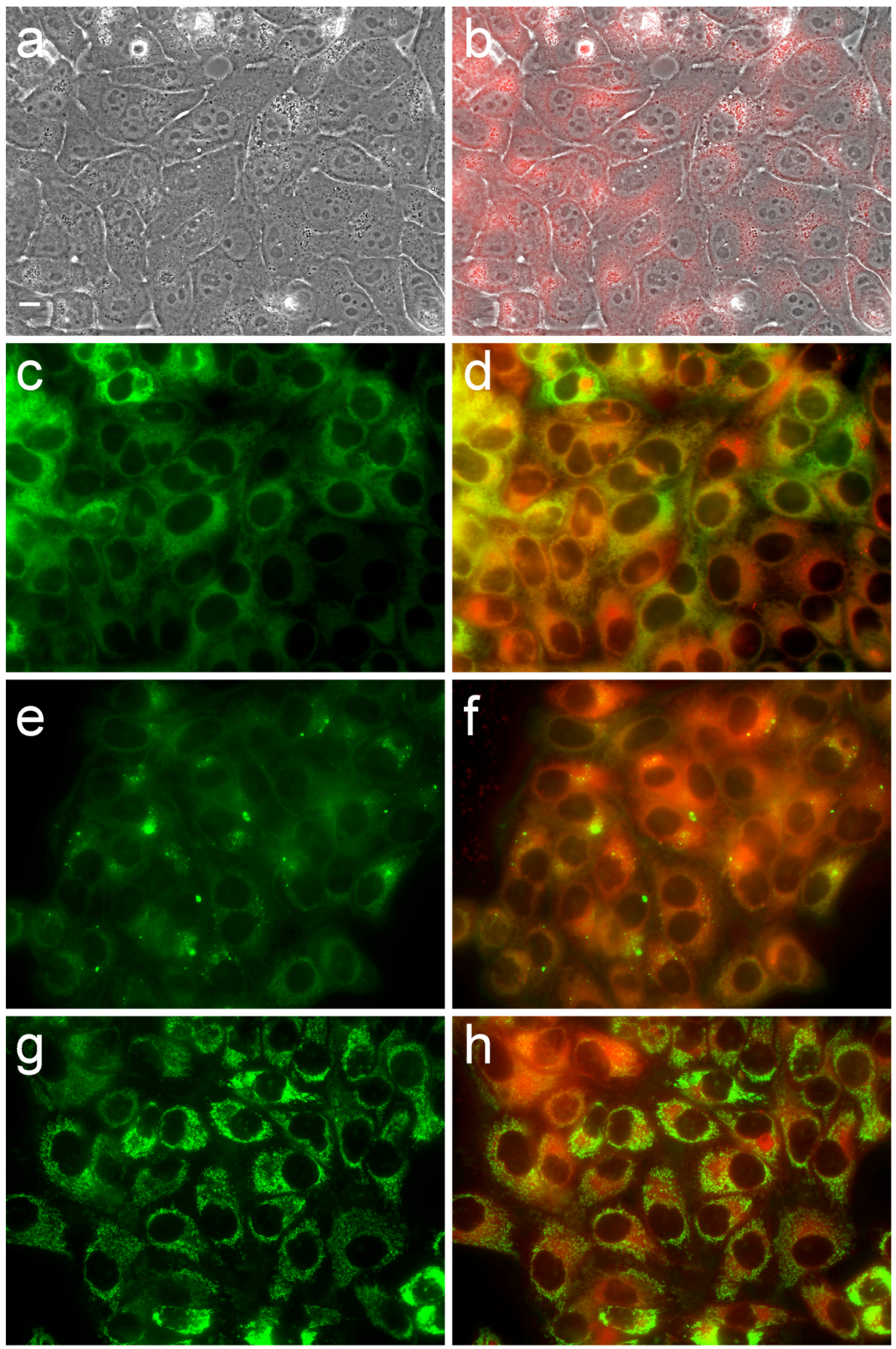

Figure S9. Subcellular localization of conjugate 6 in HEp2 cells at $10 \mu \mathrm{M}$ for $18 \mathrm{~h}$. (a) phase contrast, (b) overlay of 6 fluorescence and phase contrast, (c) DiOC 6 fluorescence, (e) LysoSensor Green fluorescence, (g) MitoTracker Green fluorescence, (d), (f) (g) overlays of organelle tracers with 6 fluorescence. Scale bar: $10 \mu \mathrm{m}$. 

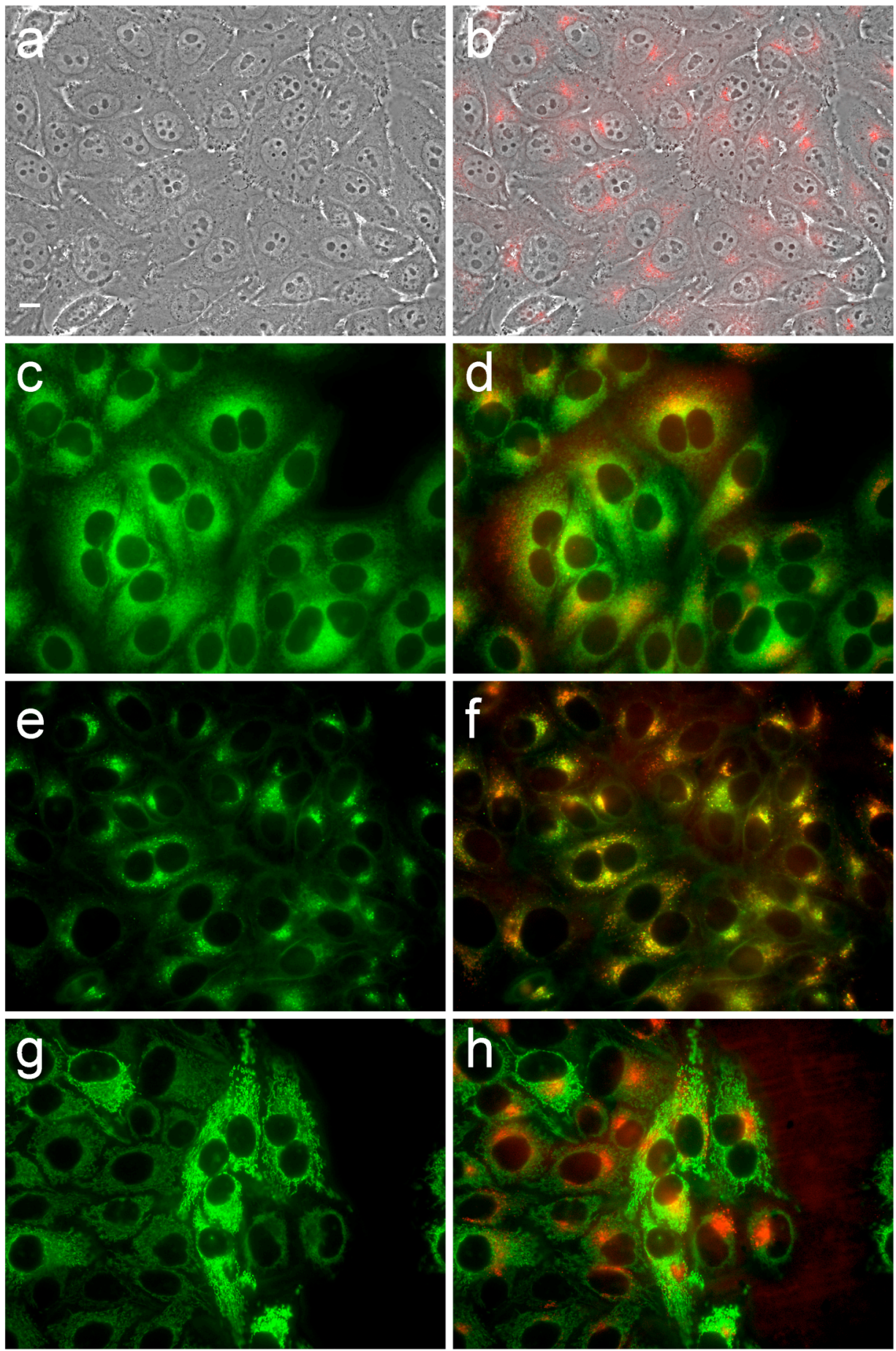

Figure S10. Subcellular localization of conjugate 11 in HEp2 cells at $10 \mu \mathrm{M}$ for $18 \mathrm{~h}$. (a) phase contrast, (b) overlay of $\mathbf{1 1}$ fluorescence and phase contrast, (c) DiOC 6 fluorescence, (e) LysoSensor Green fluorescence, (g) MitoTracker Green fluorescence, (d), (f) (g) overlays of organelle tracers with 11 fluorescence. Scale bar: $10 \mu \mathrm{m}$. 